\title{
Biogenesis of Microbial Polyhydroxyalkanoate Granules: a Platform Technology for the Production of Tailor-made Bioparticles
}

\author{
Bernd H.A. Rehm \\ Institute of Molecular Biosciences, Massey University, \\ Private Bag 11222, Palmerston North, New Zealand
}

\begin{abstract}
Biopolyester $(\mathrm{PHAs}=$ polyhydroxyalkanoates $)$ composed of hydroxy fatty acids represent a rather complex class of storage polymers synthesized by various eubacteria and archaea and are deposited as water-insoluble cytoplasmic nano-sized inclusions. These spherical shell-core particles are composed of a polyester core surrounded by phospholipids and proteins. The key enzymes of polyester biosynthesis and polyester particle formation are the polyester synthases, which catalyze the enantio-selective polymerization of $(R)$-hydroxyacylCoA thioesters to polyesters. Various metabolic routes have been identified and established in bacteria to provide substrate for polyester synthases. The role of the polyester synthases in morphogenesis and presumably self-assembly of these natural polyester particles will be described. Although not essential for particle formation, non-covalently attached proteins, the so-called phasins, can be found at the particle surface and are considered as structural proteins. A multiple alignment of 88 polyester synthases indicated an identity varying from $8 \%$ to $96 \%$ with eight strictly conserved amino acid residues. Protein engineering of polyester synthases and phasins was used to functionalize the polyester particle surface. The current knowledge enables the microbial and biocatalytic production of particles with controlled size, polyester core composition and surface functionality, which suggested numerous potential applications of these biocompatible and biodegradable nanostructures particularly in the medical field.
\end{abstract}

\section{Introduction}

Microorganisms are capable of forming a variety of intracellular and spherical inclusions. These inclusions can be surrounded by a phospholipid membrane and divided into inorganic inclusions, such as e.g. magnetosomes (iron oxide core) and organic inclusions such as e.g. biopolyester $(\mathrm{PHAs}=$ polyhydroxyalkanoates) granules (polyester core). The key enzymes of PHAbiosynthesis are the polyester synthases (also designated PHAsynthases), which catalyze the enantio-selective conversion of $(R)$-3hydroxyacyl-CoA substrates to PHAs with the concomitant release of CoA(Rehm, 2003) (Fig. 1). These biopolyesters are deposited as unique water-insoluble inclusions by eubacteria and archaea, when a carbon source is available in excess and other nutrients are growth-limiting (Fig. 2). Upon carbon starvation the polyester serves as reserve polymer and is mobilized by intracellular PHA depolymerases, which were found to be attached to the granule surface (Gao et al., 2001). Currently more than 88 different polyester synthases were identified, cloned and assigned (Rehm and Steinbüchel, 1999; Rehm, 2003; Stubbe and Tian, 2003). The alignment of the publicly available primary structures showed an overall identity of $8 \%$ to $96 \%$ exhibiting only eight strictly conserved amino acid residues (Amara and Rehm, 2003). Polyester synthases are members of a new family of enzymes with unique features, particularly considering the functional role in biogenesis of these water-insoluble subcellular structures also called PHA granules and the association with a phospholipid monolayer. The self-assembly of the polyester particles requires that the soluble polyester synthases are transformed into amphipathic enzymes upon elongation of water-insoluble polyester chains, which remain covalently attached to the enzyme. Accordingly, a self-assembly process might be initiated which leads to the formation of insoluble cytoplasmic inclusions with a phospholipid monolayer and covalently attached polyester synthases at the surface. These polyester synthases can be divided into four classes, which will be discussed below. In polyester accumulating bacteria, the structural proteins called phasins can be found attached to the granule surface (Jurasek and Marchessault, 2002; Steinbüchel et al., 1995; York et al., 2002). The functional role of these non-covalently attached proteins will be discussed with respect to granule structure. Another class of non-covalently attached proteins is represented by regulator proteins involved in transcriptional regulation of PHA biosynthesis genes.

Decades of PHA research were dedicated to understand the production of these biopolymers and to investigate the isolated crystallized biopolymers, its material properties and potential application (Brandl et al., 1990; Lee and Chang, 1995; Lee and Choi, 2001; Zinn et al., 2001). With increasing awareness of the applied potential of biological and biopolymer-based self-assembly systems as well as bionanostructures, the granules formed inside the bacterial cells, which can be functionalized by bioengineering, have attracted more and more interest. One of the first patents related to ex vivo applications of engineered biopolyester nanoparticles was filed in 2002. The size, core composition and surface functionality can be highly controlled and provides a platform technology for the production of functionalized, biocompatible and biodegradable nanoparticles, which can be applied for drug delivery, diagnostics, bioseparation, protein immobilization etc. (Brockelbank et al., 2006; Peters and Rehm, 2006; Rehm, 2006a). Moreover, these bioparticles could be used to display proteins or for protein production (Barnard et al., 2005; Brockelbank et al., 2006; Rehm, $2006 b)$. The molecular tools for the production of tailormade particles will be compiled.

For correspondence: B.Rehm@massey.ac.nz

(C) Horizon Scientific Press. Offprints from www.cimb.org 


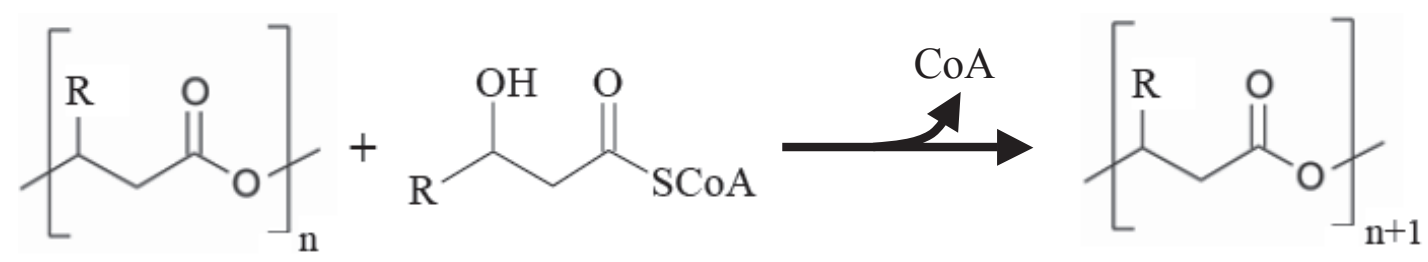

Fig. 1. Reaction catalyzed by the polyester synthases.

\section{The diversity of biopolyesters}

The biologically produced biopolyesters comprise a complex class of polyoxoesters that are synthesized by most genera of Eubacteria and even members of the family Halobacteriaceae of the Archaea (Brandl et al., 1990; Hezayen et al., 2000; Hezayen et al., 2002a; Hezayen et al., 2002b). The majority of prokaryotes synthesize poly(3-hydroxybutyric acid) (PHB) and/or other PHAs composed of medium-chain length $(R)$-3-hydroxyfatty acids (6-14 carbon atoms) as reserve material. These polyesters are deposited as spherical water-insoluble inclusions in the cytoplasm. The biopolyester constitutes the core of the granule. Meanwhile, more than 150 different hydroxyalkanoic acids are now known to occur as constituents of PHAs implying that the respective CoA thioester are accepted as substrates by the polyester synthases (Fig. 1). These water-insoluble PHAs crystallize after solvent extraction and exhibit rather high molecular weights (ranging from about $5 \times 10^{5}$ to $5 \times 10^{6}$ ), thermoplastic and elastomeric properties and some other interesting physical and material properties (Table 1). Biodegradability, thermoplastic properties and biocompatibility make these materials suitable for several applications in packaging industry, medicine, pharmacy, agriculture and food industry or as raw materials for the synthesis of enantiomerically pure chemicals and the production of paints (Anderson et al., 1990). Some Eubacteria were even able to synthesize polythioesters using mercaptoacids as carbon source and presumably employing PHA biosynthesis enzymes (Lutke-Eversloh et al., 2001). Many prokaryotic and eukaryotic organisms are able to produce low molecular weight PHB molecules which are complexed with other biomolecules such as e.g. polyphosphates and that are present at low concentrations which are three to four orders of magnitude less than storage PHAs in the cells (Addison et al., 2004; Das and Reusch, 1999, 2001; Das et al., 2002; Huang and Reusch, 1996; Reusch, 1995; Reusch et al., 1995; Reusch et al., 1997; Reusch, 2000). These complexes were found to form ion channels in the cytoplasmic membrane and to play a role in acquisition of competence in Escherichia

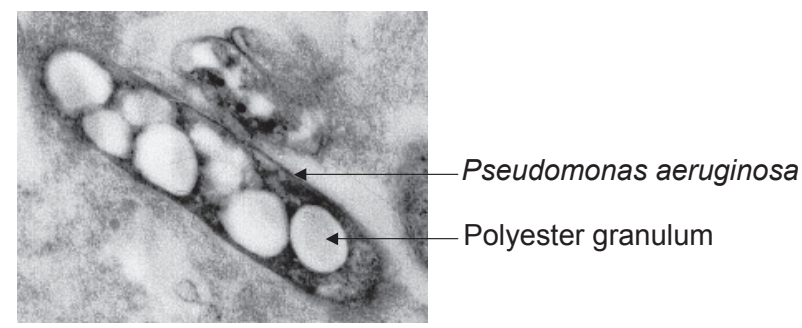

Fig. 2. Electron microscopy image of Pseudomonas aeruginosa accumulating polyester granules. coli. Unclear is how these PHB molecules are synthesized. No enzyme could be identified and no gene could be assigned in $E$. coli, which genome sequence is available, to be involved in synthesis of the low molecular weight PHB. These biosynthesis enzymes must differ significantly from the highly processive polyester synthases, which are involved in storage granule formation. The low molecular weight polyesters will be discussed below. A few eukaryotic microorganisms, such as e.g. Physarum polycephalum, are able to produce the water soluble polyester, polymalic acid, but not prokaryotes (Fischer et al., 1989).

\section{Polyester synthases are the key enzymes}

Meanwhile, the nucleotide sequences of at least 88 polyester synthase genes from at least 68 different bacteria have been obtained. With increasing numbers of published genome sequences, the numbers of putative polyester synthase genes concurrently increases. The first halobacterial polyester synthase gene candidate has been recently identified in the genome of Haloarcula marismortui (Baliga et al., 2004). Only recently, another putative polyester synthase gene was identified in the genome of an uncultivated archaebacterium belonging to Crenarchaeota (Quaiser et al., 2002). However, functionality of these archaeal polyester synthase genes has not been shown, yet. Nevertheless, the polyester synthase from an extremely halophilic archaeon has been already enzymologically and biochemically characterized (Hezayen et al., 2002a). With respect to the primary structures deduced from these sequences, the substrate specificity and the subunit composition, four major classes of polyester synthases have been proposed (Table 2).

- Class I/class II These polyester synthases comprise enzymes consisting of only one type subunit (PhaC) with molecular weights $\left(M_{w}\right)$ between 61 and $73 \mathrm{kDa}$ (Qi and Rehm, 2001). According to their in vivo and in vitro substrate specificity class I polyester synthases (Ralstonia eutropha) preferentially utilize CoA thioesters of various $(R)$-3-hydroxy fatty acids comprising 3-5 carbon atoms, whereas class II polyester synthases (Pseudomonas aeruginosa) preferentially utilize CoA thioester of various $(R)$-3hydroxy fatty acids comprising 6-14 carbon atoms (Rehm, 2003; Ren et al., 2000a).

- Class III These polyester synthases (Allochromatium vinosum) comprise enzymes consisting of two different types of subunits: (i) the PhaC subunit $\left(M_{\mathrm{w}}\right.$ of about $40 \mathrm{kDa}$ ) exhibiting amino acid sequence similarity from $21 \%$ to $28 \%$ to class I and II polyester synthases and (ii) the PhaE subunit $\left(M_{w}\right.$ of about $40 \mathrm{kDa}$ ) with no similarity to polyester synthases. These polyester synthases prefer CoA thioesters 
Table 1. Chemical structures of the two major classes of biopolyesters and comparison of material properties with polypropylene (PP) (modified according to Rehm, 2003).<smiles>CCCCCCCCCC(O)CC(=O)OC(CCCCCCC)CC(=O)OC(CCCCC)CC(=O)OC(CCC)CC(O)O</smiles>

\begin{tabular}{lccc} 
Properties & PHA $_{\mathrm{SCL}}$ & $\mathrm{PHA}_{\mathrm{MCL}}$ & $\mathrm{PP}$ \\
\hline $\mathrm{T}_{m}\left({ }^{\circ} \mathrm{C}\right)$ & 177 & 61 & 176 \\
$\mathrm{~T}_{g}\left({ }^{\circ} \mathrm{C}\right)$ & 2 & -36 & -10 \\
Crystallinity (\%) & 70 & 30 & 60 \\
Elongation at break (\%) & 5 & 300 & 400
\end{tabular}

of $(R)$-3-hydroxy fatty acids comprising 3-5 carbon atoms (Liebergesell et al., 1992; Liebergesell and Steinbüchel, 1992).

- Class IV These polyester synthases (Bacillus megaterium) are similar to the class III polyester synthases, whereas the subunit PhaE is replaced by PhaR $\left(M_{w}\right.$ of about $20 \mathrm{kDa}$ ) (McCool and Cannon, 1999, 2001).

This classification does not allow inclusion of the synthases from Thiocapsa pfennigii (two different subunits with strong similarity of PhaC subunit of to class III polyester synthases), from Aeromonas punctata (one type of subunit with strong similarity to class I polyester synthases) and from Pseudomonas sp. 61-3 (PhaC1 and PhaC2 with strong similarity to class II polyester synthases) regarding substrate specificity (Fukui and Doi, 1997; Liebergesell et al., 2000; Matsusaki et al., 1998). The T. pfennigii polyester synthase exerts a broad substrate specificity comprising CoA thioesters of short-chain-length (3-5 carbon atoms) as well as medium-chain-length (6-14 carbon atoms) 3hydroxy fatty acids. The $A$. punctata synthase catalyses synthesis of a copolyester of 3-hydroxybutyrate and 3hydroxyhexanoate. Hybrid class III polyester synthases were generated by interchanging the PhaE and PhaC subunits from $A$. vinosum and $T$. pfennigii that the

Table 2. The four classes of polyester synthases (modified according to Rehm, 2003).

\begin{tabular}{|c|c|c|c|}
\hline Class & Subunits & Species & Substrate \\
\hline I & $\begin{array}{l}\text { PhaC } \\
\sim 60-73 \mathrm{kDa}\end{array}$ & Cupriavidus necator & $\begin{array}{c}3 \mathrm{HA}_{\mathrm{SCL}}-\mathrm{CoA} \\
(\sim \mathrm{C} 3-\mathrm{C} 5) \\
4 \mathrm{HA}_{\mathrm{SCL}}-\mathrm{CoA}, \\
5 \mathrm{HA}_{\mathrm{SCL}}-\mathrm{CoA}, 3 \mathrm{MA}_{\mathrm{SCL}}-\mathrm{CoA}\end{array}$ \\
\hline II & $\underset{\sim 60-65 \mathrm{kDa}}{\text { PhaC }}$ & Pseudomonas aeruginosa & $\begin{array}{c}3 \mathrm{HA}_{\mathrm{MCL}-\mathrm{CoA}} \\
(\sim \mathrm{C} 5)\end{array}$ \\
\hline III & $\begin{array}{c}\text { PhaCPhaE } \\
\sim 40 \mathrm{kDa} \sim 40 \mathrm{kDa}\end{array}$ & Allochromatium vinosum & $\begin{array}{c}3 \mathrm{HA}_{\mathrm{SLL}_{\mathrm{SL}}-\mathrm{CoA}} \\
\left(3 \mathrm{HA}_{\mathrm{MCL}}-\mathrm{CoA}[\sim \mathrm{C} 6-\mathrm{C} 8]\right. \\
4 \mathrm{HA}-\mathrm{CoA}, 5 \mathrm{HA}-\mathrm{CoA})\end{array}$ \\
\hline IV & $\begin{array}{c}\text { PhaCPhaR } \\
\sim 40 \mathrm{kDa} \sim 22 \mathrm{kDa}\end{array}$ & Bacillus megaterium & $3 \mathrm{HA}_{\mathrm{SCL}}-\mathrm{CoA}$ \\
\hline
\end{tabular}


respective PhaC subunit determines substrate specificity (Liebergesell et al., 2000). Interestingly, the polyester synthases PhaC1 and PhaC2 from Pseudomonas sp. 61-3 catalyze the polymerization of a copolyester of 3hydroxybutyrate and medium-chain-length 3-hydroxy fatty acids (Matsusaki et al., 1998). In vivo substrate specificity of the Cupriavidus necator (formerly Wautersia eutropha, Ralstonia eutropha and Alcaligenes eutrophus) polyester synthase produced in recombinant $E$. coli suggested that even this class I synthase is accommodating mediumchain-length 3-hydroxy fatty acid-CoA thioesters as substrate (Antonio et al., 2000; Dennis et al., 1998). Overall, these data suggested a rather broad substrate specificity of polyester synthases.

Extensive comparison of the 88 polyester synthases revealed that these enzymes from various bacteria exhibit strong similarity ranging from $8 \%$ to $96 \%$ identity. Six conserved blocks could be identified based on conserved amino acid sequence regions, whereas the $\mathrm{N}$ terminal region (about 100 amino acids relative to class I polyester synthases) is highly variable (Rehm et al., 2002) (Fig. 3). The $\mathrm{N}$-terminal region is also dispensable as revealed by the analysis of truncated $C$. necator polyester synthases that lacked 100 amino acids, whereas the more conserved C-terminal region appears to be required for enzyme activity (Peters and Rehm, 2005; Rehm et al., 2002; Schubert et al., 1988; Schubert et al., 1991). Overall, eight amino acid residues are identical in all known 88 polyester synthases suggesting an important function of these residues. Comparison of the hydrophilicity profiles from class I and II polyester synthases showed only one major difference at positions 100-130 (class I polyester synthase) or 80-110 (class II polyester synthase), suggesting that this region might contribute to substrate specificity. The $\mathrm{C}$ terminus (about 40 amino acid residues) appears to be rather conserved and hydrophobic among all class I and II polyester synthases, suggesting that this region might function as binding domain attaching the synthase to the hydrophobic polyester core (Rehm et al., 2002). In contrast, PhaC subunits of class III and IV synthase contain no hydrophobic $C$ terminus, but the second subunit PhaE or PhaR, respectively, possess a hydrophobic $\mathrm{C}$ terminus, which might also mediate binding to the polyester core.
Only recently the PHB synthase from an extremely halophilic archaebacterium was identified and characterized representing presumably a new class of synthases (Hezayen et al., 2002a). This enzyme could be distinguished by heat-stability up to $60^{\circ} \mathrm{C}$ at which the enzyme still exhibited about $90 \%$ of the maximum enzyme activity, which was obtained at $40^{\circ} \mathrm{C}$. The soluble archaeal $\mathrm{PHB}$ synthase was only active at high salt concentration, whereas the granule-bound PHB synthase was almost independent of the salt concentration.

\section{Genetics of polyester biosynthesis enzymes}

The biopolyester biosynthesis genes are often clustered in the bacterial genomes. In C. necator, which has been studied in detail, the genes encoding polyester synthase (phaC), $\beta$-ketothiolase (phaA) and NADP-dependent acetoacetyl-CoA reductase ( $p h a B$ ) are organized in the phaCAB operon (Peoples and Sinskey, 1989a, 1989b; Schubert et al., 1988; Slater et al., 1988). Besides, the frequently found genetic organization of $C$. necator among PHB accumulating bacteria, some bacteria show a different gene order but at least the PHB synthase gene is colocalized with other PHB biosynthesis genes. Some species like $P$. denitrificans contain adjacent to the polyester synthase further genes like phaP (encoding phasin) and phaR (encoding regulator protein) related to PHA biosynthesis. An operonic organization of PHA biosynthesis genes, related to the short-chain-length PHA biosynthesis (class I polyester synthase gene) was found among the $\beta$-proteobacteria such as e.g. $C$. necator, Burkholderia sp., Alcaligenes latus and Delftia acidovorans.

The pseudomonads, which accumulate mediumchain-length PHAs exerting elastomeric properties, contain two different genes encoding class II synthases that are separated by the structural gene phaZ encoding a putative intracellular PHA depolymerase (Hoffmann and Rehm, 2004, 2005; Timm and Steinbüchel, 1992). Only one of these polyester synthase genes is required for medium-chain-length PHA biosynthesis (Langenbach et al., 1997; Pham et al., 2004). The phaD gene is located directly downstream of the second synthase gene, but upstream of the genes phal and phaF, which are transcribed in opposite direction. Phal and PhaF

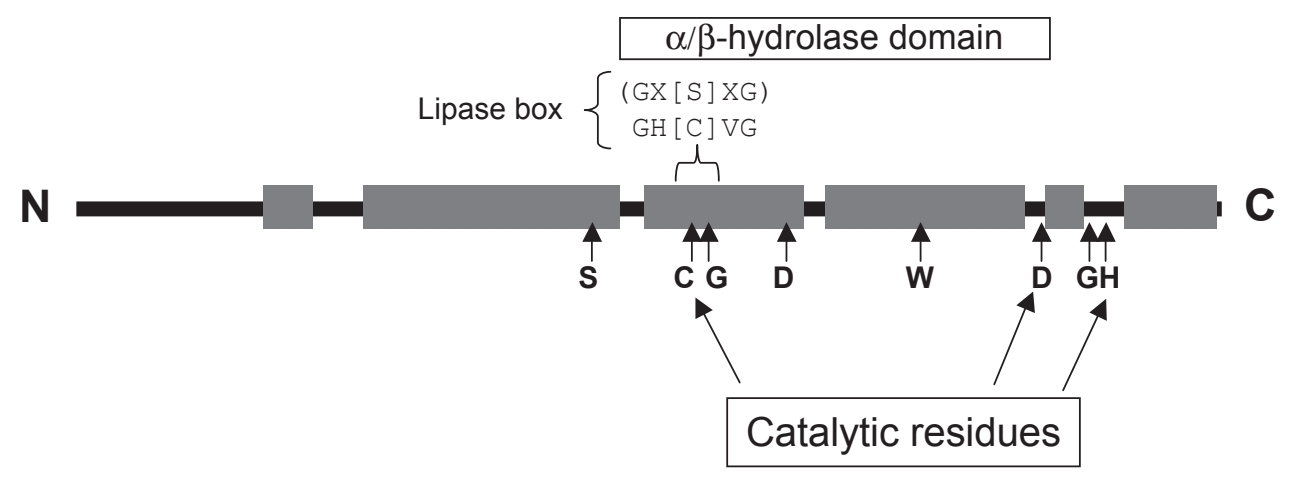

Fig. 3. Primary structure of the polyester synthase from $C$. necator. The position of conserved block regions is indicated as grey rectangles. The position of the eight conserved amino acid residues is indicated by arrows. The position of the conserved $\alpha / \beta$-hydrolase domain is represented by the upper rectangle. 
are considered as structural and regulatory proteins (Hoffmann and Rehm, 2004, 2005; Prieto et al., 1999). Interestingly, in pseudomonads the genes encoding for enzymes, such as e.g. the transacylase (PhaG) or the enoyl-CoA hydratase (PhaJ), which are directly involved in provision of substrate for the polyester synthase are not co-localized (Rehm et al., 1998; Tsuge et al., 2000).

The class III polyester synthase genes phaC and phaE are co-localized in the respective genomes comprising presumably a single operons (Liebergesell et al., 1992; Liebergesell et al., 1993).

The class IV synthase genes are found in bacteria of the genus Bacillus and comprise phaR and phaC which are separated by phaB (McCool and Cannon, 1999, 2001).

\section{Polyester synthases}

\section{Structural features and topological models}

Currently no structural data of polyester synthases are available. The secondary structure content was deduced by predictions implementing the multiple alignment of synthases. The use of JPred indicated that polyester synthases are mainly composed of variable loops (49.7\%) and $\alpha$-helical $(39.9 \%)$ secondary structures, whereas only $10.4 \%$ were proposed as $\beta$-sheet secondary structures (Cuff and Barton, 2000). In contrast, circular dichroism spectroscopy suggested that the synthase from $P$. aeruginosa is composed of the following secondary structures: $10 \% \alpha$-helix, $50 \% \beta$-sheet and $40 \%$ random coil (Rehm et al., 2001).

Purified polyester synthases exist in vitro in an equilibrium of monomeric and dimeric forms whereas dimerization is significantly induced in the presence of substrate or trimeric CoA analogs (3-hydroxybutyryl) CoA, respectively (Rehm et al., 2001; Wodzinska et al., 1996). In the presence of trimeric analogs a reduction in enzymatic lag phase was observed, and the specific activity increased (Muh et al., 1999). This suggested that the dimer is significantly more active than the monomer when this putative primer is absent. Radiolabeled trimeric CoA analogs were detected to be covalently bound to the polyester synthase of $C$. necator, but revealing only radiolabeling of the dimer as was shown by gel-filtration chromatography (Wodzinska et al., 1996).

Gold-labeled anti-PHA synthase antibodies were used for immunoelectron microscopy studies of granules isolated from $A$. vinosum and $C$. necator, which clearly indicated the presence polyester synthase complexes and polyester synthases, respectively, at the surface of the PHA granule (Gerngross et al., 1993; Liebergesell et al., 1994). This homogenous population of particles observed on granules from $A$. vinosum measuring $11.2-12.8 \mathrm{~nm}$ in diameter and data derived from gel filtration chromatography suggested that this synthase might be composed of ten subunits (Liebergesell et al., 1994; Mayer et al., 1996). Thus, the active synthase might consist in vitro of two subunits and the polyester synthase associated with in vivo PHA granules might be composed of ten subunits in $A$. vinosum. Gel-filtration chromatography analysis of PHA granule associated polyester synthase of $A$. vinosum indicated that the tertiary structure resembles a dodecamer. When considering that the polyester synthase is composed of the two subunits PhaC and PhaE, this polyester synthase might form a hexameric protein complex (Jia et al., 2000).

Six conserved blocks and eight conserved amino acid residues were identified based on the multiple alignment of the amino acid sequences of polyester synthases (Rehm, 2003). The alignment also revealed that all polyester synthases contain a conserved lipase-like box (G-X-[S/ $\mathrm{C}]-\mathrm{X}-\mathrm{G}$ ) in which the catalytic site serine of the lipase is replaced with a cysteine in the polyester synthase (Fig. 3). A site-specific mutagenesis approach to convert the polyester synthase into a lipase by replacing the cysteine residue by a serine residue was not successful (Amara and Rehm, 2003). Interestingly, this mutant still showed polyester synthase activity suggesting the formation of an oxoester acyl-enzyme intermediate.

In order to identify domain features, the conserved domain (CD) homology search was performed which strongly suggested that polyester synthases contain the $\alpha / \beta$-hydrolase domain at the $\mathrm{C}$-terminal half of the protein (Fig. 3). A BlastP sequence homology search using the class III A. vinosum polyester synthase (PhaC) revealed significant homology to lipases, particularly to the lipase from Burkholderia cepacia with the predicted catalytic site cysteine-149 aligned with the active site serine of the lipase (Jia et al., 2000). Three lipases and the three class III polyester synthases from A. vinosum, Thiocystis violacea and Synechocystis sp. PCC6803 were aligned using ClustalW and showed an overall significant homology. In this alignment the active site nucleophile serine- 87 within the lipase box of the lipase was aligned with the lipase-like box of the polyester synthase cysteine (cysteine-149 from $A$. vinosum polyester synthase). This ClustalW alignment indicated an about $19 \%$ identity of the $A$. vinosum polyester synthase with the $B$. cepacia lipase by inserting several gaps. The multiple alignment was used applying the crystallographically resolved protein structure of the $B$. cepacia lipase as input for SWISS-MODEL protein threading. A rather accurate structural model was obtained between residues 131-175, which comprises the lipase box as well as the $\alpha / \beta$-hydrolase domain (Jia et al., 2000). Further threading algorithms such as e.g. SAMT98, 3D-PSSM and the UCLA Foldserver were applied using the entire polyester synthase sequence. This study resulted in a comparable structural model revealed that the conserved residues histidine-331, aspartate-302 and histidine-303 are close to the core structure (Jia et al., 2000). However, the residue cysteine-130, which has been previously identified to be important for covalent catalysis (Muh et al., 1999) was not residing in the core structure and is therefore not considered to function in covalent catalysis. Nevertheless, cysteine-149 resides at the conserved nucleophile elbow and replacement of this residue strongly reduced enzyme activity (Jia et al., 2000).

A similar approach was used to develop structural models of the class II polyester synthase PhaC1 from $P$. aeruginosa and PhaC from $C$. necator, which did also reveal significant homology to enzymes related to the superfamily of $\alpha / \beta$-hydrolases (Amara and Rehm, 2003). The conserved domain (CD) homology search strongly 
suggested that both polyester synthases contain the $\alpha / \beta$-hydrolase domain. The CD alignment showed that the region of amino acid residues 249-492 exhibited $30 \%$ similarity and $17 \%$ identity to the conserved $\alpha / \beta$ hydrolase domain. The conserved and proposed catalytic residues of both polyester synthases aligned with amino acid residues constituting the catalytic triad in enzymes belonging to $\alpha / \beta$-hydrolases. A structural model of PhaC1 from $P$. aeruginosa was developed based on similarity to the epoxide hydrolase (1ek1) from mouse, which structure was used as template. Recently, a structural model was also developed for the class I polyester synthase from $C$. necator based on similarity to the structurally resolved lipase from Burkholderia glumae (Rehm et al., 2002). Both polyester synthase models were refined by energy minimization which was performed employing the consistent valence force field (CVFF) implemented in DISCOVER. The stereochemistry of the model structures was evaluated with the program PROCHECK and the residue environment was analyzed using the VERIFY $3 \mathrm{D}$ program. Both models indicate that these polyester synthases are also members of the protein family containing an $\alpha / \beta$-hydrolase fold as found in prokaryotic lipases. The $C$. necator synthase has been studied in detail and most of the mutagenesis approaches have been performed with this class I polyester synthase (Rehm, 2003). In summary, the mutational analysis indicated that the variable non-conserved $\mathrm{N}$ terminus (the first about 100 amino acid residues), which could be altered by insertion of Smal restriction sites as well as by a deletion of the first $100 \mathrm{~N}$ terminal amino acid residues without losing enzyme activity, is not essential for polyester synthase activity. Interestingly, some site-specific mutations in this $\mathrm{N}$ terminal region did even enhance enzyme activity (Normi et al., 2005; Zheng et al., 2006). Deletions of C terminal amino acids (5 and 12 amino acid residues) inactivated the polyester synthase suggesting that the $C$ terminus, although not present in the class III polyester synthase, but conserved among class I and II polyester synthases, is essential for enzymatic activity (Rehm et al., 2002). In addition, the $C$ terminus of the polyester synthases seems to be rather hydrophobic suggesting that this region interacts with the hydrophobic core of PHA granules. Deletions between the conserved blocks 2 and 3 as well as 3 and 4, respectively, were abolishing polyester synthase activity (Rehm et al., 2002), but Smal restriction site insertions between blocks 2/3, 3/4 and 5/6, respectively, were tolerated indicating that these regions are not adjacent to the core structure and thus more likely to be surface exposed. Five Smal restriction site insertions in the conserved block 2 were not permissive and caused inactivation of the polyester synthase indicating that this region might be structurally relevant and unlikely to be surface exposed. A random linker insertion approach using the class I polyester synthase from $C$. necator showed that a 19 amino acid residues comprising insertion is only tolerated in the variable $\mathrm{N}$ terminus (Peters et al., 2006). This investigation did also suggest that the remainder of the synthase comprising the $\alpha / \beta$-hydrolase fold region is structurally constraint. Numerous site-specific mutations had been introduced based on the multiple amino acid sequence alignment as well as with the aid of the topological models to illuminate the functionality of certain amino acid residues in the catalytic mechanism (Rehm, 2003, 2006a).

Fusion proteins composed of the $\mathrm{N}$ terminal part of the class II polyester synthase from $P$. aeruginosa and the $\mathrm{C}$ terminal part of the class I polyester synthase from $C$. necator indicated that fusion points located in the $\alpha / \beta$-hydrolase fold region are not tolerated (Rehm et al., 2002). This was confirming the putative presence of a functionally important $\alpha / \beta$-hydrolase domain. Furthermore, the fusion points were not leading to an active hybrid polyester synthase were located in predicted and structurally conserved $\alpha$-helical regions. However, a fusion point at position 289 relative to the amino acid sequence of the $C$. necator polyester synthase and located at a variable surface-exposed loop suggested by the protein model resulted in an active hybrid polyester synthase. Accordingly, this suggested that the first 288 amino acid residues of $C$. necator polyester synthase could be replaced by the $\mathrm{N}$ terminus of a class II polyester synthase and it provided evidence for the importance of the $\alpha / \beta$-hydrolase fold region.

\section{Catalytic reaction mechanism}

The conserved residues cysteine-319, aspartate-480 and histidine-508 of the class I polyester synthase from $C$. necator were the first be investigated by sitespecific mutagenesis which provided evidence for direct involvement in covalent catalysis (Gerngross et al., 1994; Jia et al., 2001) (Fig. 3). In addition, the highly conserved tryptophan-425 was replaced by alanine strongly reducing enzyme activity. Tryptophan-425 has been suggested to be involved in protein-protein interaction by generating a hydrophobic surface for dimerization of PhaC subunits (Gerngross et al., 1994).

The homologous amino acid residues cysteine-149, histidine-331, aspartate-302 of $\mathrm{PhaC}$ from $A$. vinosum were subjected to site-specific mutagenesis which almost abolished enzymatic activity. These data strongly suggested an involvement in covalent catalysis (Jia et al., 2000).

Accordingly, the conserved catalytic triad residues of class II polyester synthase from $P$. aeruginosa were subjected to site-specific mutagenesis (Amara and Rehm, 2003). The corresponding cysteine-296 and aspartate-452, respectively, were found to be essential for enzyme activity as was found for the other classes of polyester synthases. Interestingly, replacement of the putative general base catalyst histidine-480 did only impair enzyme activity, but replacement of the conserved cysteine and aspartic acid inactivated the enzyme. Since a general base catalyst would be required for covalent catalysis according to the catalytic mechanism of a/bhydrolases, scientist searched for another possible base catalyst. Inspection of the structural model of the class II polyester synthase showed another conserved candidate histidine- 453 located adjacent to the protein core, the highly conserved histidine-480 as well as to the catalytic nucleophile. Replacement of this histidine did strong impair enzyme activity suggesting that the two histidines functionally replace each other. A further difference to the class I and III synthases was discovered 
by replacing the class II synthase catalytic cysteine-296 by serine which did not result in an inactive enzyme (Amara and Rehm, 2003). However, the replacement of the conserved tryptophan-398, which might be part of the hydrophobic surface required for polyester synthase dimerization, caused inactivation of the enzyme. Thus this tryptophan-398 plays an essential role presumably in protein dimerization as postulated for class I synthases (Amara and Rehm, 2003; Jia et al., 2001). Regarding the implementation of amino acid residues for covalent catalysis the class II enzymes from pseudomonads represent a rather distinct group with unique features not found in class I and III enzymes.

In all structural models the amino acid residues presumably constituting the catalytic triad or involved in covalent catalysis were identified as being adjacent to the core structure of with the putative active site nucleophile cysteine located at the elbow of the strand-elbowhelix motif. In the class II polyester synthase the highly conserved histidine residue, which functions as a general base catalyst in $\alpha / \beta$-hydrolases, was functionally replaced by an adjacent histidine residue also close to the core structure.

Since, polyester synthases contain a cysteine residue as catalytic nucleophile, the general base catalyst histidine would be sufficient for nucleophilic activation as has been shown for cysteine proteases (Turk et al., 1997). Studies with the saturated trimer of 3-HB-CoA in which the terminal hydroxyl has been replaced with a tritium $\left(\left[{ }^{3} \mathrm{H}\right]-\right.$ sT-CoA) and a cysteine-149-alanine mutant provided first direct evidence for the important role of cysteine-149 of class III polyester synthase in covalent catalysis and the importance of histidine-331 as general base catalyst in the activation of this cysteine. These studies did also indicate that aspartate-302 did not contribute to the catalytic triad but might be required as a general base catalyst activating the 3-hydroxyl group of 3-hydroxybutyryl-CoA for nucleophilic attack to generate the oxygen ester linkage, thus more being involved in elongation than covalent binding of the substrate to cysteine-149.

The current mechanistic model for polyester synthases is based on data from studies with the artificial primer (sTCoA). Recently, the aspartate-302-alanine mutant of the $A$. vinosum class III synthase was studied in more detail using radiolabeled 3-hydroxybutyryl-CoA suggesting that oligomeric 3-HBs was covalently bound to PhaC (Tian et al., 2005a). These in vitro results again suggested a more important function of aspartate-302 in elongation than activation of the catalytic cysteine. Tian et al. (Tian et al., 2005b) did also demonstrated by using different substrate to enzyme ratios and monitoring PHB formation at PhaC that the synthase initiates polymerization through selfpriming. Furthermore, it was proposed that the synthase is capable of chain termination and reinitiation. Thus, in polyester synthases the second general base catalyst (aspartate) is required to activate the 3-hydroxyl of the 3-hydroxybutyryl-CoA or the bound 3-hydroxybutyryl to enable nucleophilic attack on the acylated enzyme and/or self-priming (Fig. 4).

Overall, the $\alpha / \beta$-hydrolase-based catalyticmechanism, particularly considering lipases and cysteine proteases, provides a good model for classes I-III of polyester synthases as supported by mutational analysis of the C. necator class I polyester synthase, the $A$. vinosum class III polyester synthase and the $P$. aeruginosa class II polyester synthase (Rehm, 2003).

Regarding the chain elongation mechanism Griebel et al. (Griebel et al., 1968; Griebel and Merrick, 1971) suggested that in analogy to fatty acid synthases two thiol groups of the polyester synthases are involved in the polymerization reaction (Witkowski et al., 1997). Since only one cysteine residue (e.g. cysteine-296 from $P$. aeruginosa polyester synthase) is present in all polyester synthases (Fig. 3), studies were performed to identify the
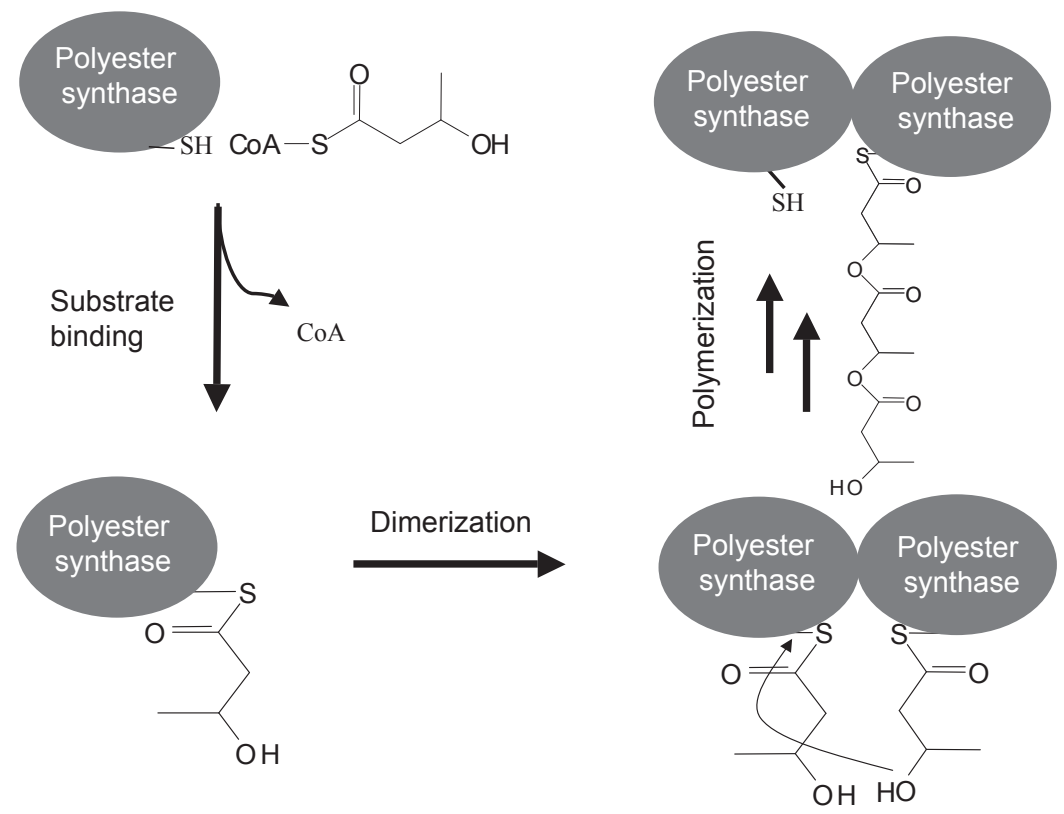

Fig. 4. Model of the catalytic mechanism of polyester synthase. 
second thiol group (Amara and Rehm, 2003; Gerngross et al., 1994; Hoppensack et al., 1999; Yuan et al., 2001). Initially, scientists assumed that the weakly conserved cysteine-459 of the $C$. necator synthase could play such a role in the catalytic cycle, providing the second thiol group, but site-specific mutagenesis clearly suggested that this amino acid residue is not required for catalytic activity. The rather conserved serine-260 of the $C$. necator polyester synthase was also suggested to play such a functional by being a potential target for covalent posttranslational modification with 4-phosphopantetheine. Thus the second thiol group could be provided via modification as found in fatty acid synthases. Radiolabeling experiments were conducted analyzing polyester synthases from $C$. necator, A. vinosum and $P$. aeruginosa in E. coli SJ16 (panD) which allows detection of 4-phosphopantetheinylated polyester synthases by autoradiography. The experiments indicated that polyester synthases from C. necator and $A$. vinosum belonging to class I and class III enzymes, respectively, were modified by 4-phosphopantetheine, but not the class II polyester synthase from $P$. aeruginosa. It is however still intriguing that no peptide could be isolated from the modified class I or class III polyester synthases, which is covalently modified by 4-phosphopantetheine. In another study functional low level expression of polyester synthase gene from $C$. necator in a $\beta$-alanine auxotrophic mutants of $C$. necator with subsequent analysis of 4phosphopantetheinylated proteins did not indicate covalent posttranslational modification by 4-phosphopantetheine. Nevertheless, replacement of amino acid residue serine260 by alanine and threonine, respectively, abolished in vivo and in vitro activity of polyester synthase from C. necator suggested another important functional role. Since, polyester synthase genes from bacteria have been also expressed in numerous organisms from different kingdoms, a specific posttranslational modification systems for polyester synthases seems not to be required. Currently, the active polyester synthase has been suggested to form a homodimer considering class I and II polyester synthases and a multimeric heterodimer (PhaC and PhaE) considering class III polyester synthases. Thus each PhaC subunit provides a conserved cysteine residue making sufficient cysteine residue available for catalytic reaction.

The initially postulated catalytic mechanism based on the catalytic reaction mechanism of fatty acid synthases (Griebel et al., 1968), has now been refined considering a reaction mechanism found in $\alpha / \beta$-hydrolases. Now two thiol groups provided by cysteine residues are thought to be involved in covalent catalysis. One thiol group serves as the accepting site for the substrate 3-hydroxybutyrylCoA and the second thiol group serves for priming and elongation. However, there is still some evidence supporting the fatty acid synthase mechanism such as e.g. (i) the requirement of the conserved serine-260 of the C. necator polyester synthase for enzyme activity (Hoppensack et al., 1999); (ii) the sensitivity towards the serine-specific inhibitor PMSF (Amara and Rehm, 2003; Jia et al., 2000) and (iii) the respective conserved serine residues are close to the core structure in the respective synthase models. Contradicting data with respect to covalent modification by 4-phosphopantetheinylation are still not allowing to fully exclude a similar mechanism as found in fatty acid synthases.

A catalytic mechanism similar to the catalytic mechanism of lipases which belong to the $\alpha / \beta$-hydrolase superfamily of proteins has been proposed (Ollis et al., 1992; Schrag and Cygler, 1997). All hydrolases are considered to contain catalytic triads composed of the active site nucleophile (serine, cysteine or aspartate), an acidic amino acid (aspartate or glutamate) and a histidine always being in this order regarding primary structure. The nucleophile was always located at the elbow of a strand-elbow-helix motif. Since lipases are subject to interfacial activation at the lipid-water interface, similarities to polyester synthases catalyzing a reaction at the waterpolyester interface are obvious. Accordingly, the attached synthase showed a significantly increased enzymatic activity, when compared with the soluble enzyme. The respective water-soluble substrate is presumable bound to water-exposed domains of the polyester synthase enabling synthesis of the growing polyester chain into the core of the polyester granule.

The soluble polyester synthase converts into an amphipathic molecule upon availability of substrate and subsequent hydrophobic polyester chain elongation (Rehm, 2003). This leads to self-assembly of so-called $\mathrm{PHA}$ granules with the hydrophobic PHA in the core and the active polyester synthases at the surface, which represents the water-polyester interface. Analysis of the granule-associated polyester synthase from $C$. necator revealed an about 40-fold increased enzyme activity when compared with the soluble enzyme (Gerngross and Martin, 1995). These data suggested that interfacial activation occurred and that a lid-like structure as found in lipases and also found in the $C$. necator polyester synthase model might also play a role in polyester synthases (Rehm et al., 2002).

\section{Modified polyester synthases obtained by random mutagenesis}

Since properties of polyester synthases determine the polyester composition and molecular weight as well as strongly impact on efficiency of production, the polyester synthases were focus of directed evolution experiments (Amara et al., 2002; Kichise et al., 2002; Rehm et al., 2002; Sheu and Lee, 2004; Taguchi and Doi, 2004; Takase et al., 2003). The aim of these studies was to enhance the specific activity and to change substrate specificity in order to efficiently obtain tailor-made biopolyester. PCRbased in vitro evolution was applied to the $A$. punctata FA440 synthase which catalyses the formation of a PHA random copolyester of 3-hydroxybutyrate and 3hydroxyhexanoate, which is a tough and elastomeric material compared to the PHB homopolyester (Kichise et al., 2002). The two mutations N149S and D171G, respectively, which are not conserved among the polyester synthases led to strongly enhanced in vivo and in vitro enzyme activity. Interestingly, the 3-hydroxyhexanoate molar fraction was increased up to $18 \mathrm{~mol} \%$ as compared to the wild type (10 mol\%).

In vitro evolution was also used to isolate mutants of C. necator polyester synthase gene encoding for enzymes with enhanced activity. Mutations which enhance activity 
of the enzyme were identified by multi-step mutations including activity loss and intragenic suppression-type activity reversion. This study enabled isolation of a modified polyester synthase harboring a F420S mutation resulting in a 2.4-fold increase in specific activity toward $3 \mathrm{HB}-\mathrm{CoA}$, when compared to the wild-type (Taguchi et al., 2002). A beneficial G4D N-terminal mutation important for the enhancement of both PHB content in dry cells and $\mathrm{PhaC}$ level in vivo was recently identified by in vitro evolution (Normi et al., 2005).

In addition random mutagenesis was also used to alter and improve enzyme properties of the class II synthases. Recently, in vitro evolution of the polyester synthase gene phaC1 from Pseudomonas sp. 61-3 has been performed and a positive mutant of polyester synthase, E130D led to 10-fold higher (1.0 wt\%) accumulation of $\mathrm{PHB}$ from glucose in recombinant $E$. coli, when compared to recombinant $E$. coli harboring the wild-type polyester synthase gene $(0.1$ $w t \%)$. The E130D mutation also resulted in the production of copolymer with a slight increase in $3 \mathrm{HB}$ composition, compared to copolymer produced by the wild-type polyester synthase. In vitro enzyme activities of the E130D polyester synthase toward various 3-hydroxyacylCoAs (4-10 carbons in length) were all higher than those of the wild-type enzyme. The combination of the E130D mutation with other beneficial mutations, such as S325T and Q481K, exhibited a synergistic effect on in vivo PHA production and in vitro enzyme activity (Matsumoto et al., 2005).

Single gene shuffling of a polyester synthase was firstly applied by Rehm and coworkers (Rehm et al., 2002). This study resulted in the isolation of modified synthases with reduced activity. However, one of the most promising strategies was the in vivo random mutagenesis of the polyester synthase gene from $A$. punctata, which was performed employing the mutator strain Escherichia coli XL1-Red (Amara et al., 2002). More than 200,000 mutants were screened on Nile red-containing medium and five mutants represented as colonies with enhanced fluorescence were isolated. Four of these mutants showed enhanced in vivo and in vitro polyester synthase activity. The single mutation $\mathrm{F} 518 \mathrm{I}$ resulted in a five-fold increase in specific polyester synthase activity, whereas the mediated PHA accumulation increased only by $20 \%$, as compared with the wild-type polyester synthase. The single mutation V214G showed a two-fold increase in specific polyester synthase activity and PHA accumulation only increased by $7 \%$. The in vitro activities of the overproducing mutants were increased by 1.1 - to 5 -fold more than the wild-type activity, whereas the amounts of accumulated PHA ranged over $107-126 \%$ of the wild type. All mutants mediated synthesis of PHAs with an increased weight average molar mass, but the molar fractions were not significantly affected. This in vivo random mutagenesis approach proved to be a powerful tool to isolate mutants showing enhanced enzyme activity.

Overall, many mutations could be identified in polyester synthases, which led to improved enzymatic properties, but the functional role of the affected amino acid residues remains unknown. Thus, biochemical and enzymological studies of wild-type polyester synthases as well as modified polyester synthases should be conducted to further illuminate structure-function relationships and the catalytic mechanism of the polyester synthase. Ultimately, resolution of the three-dimensional structure of the polyester synthase by X-ray analysis will be a crucial step towards the understanding of this interesting class of enzymes.

\section{Substrate specificity}

The substrate specificity of polyester synthases strongly determines the composition of the synthesized PHA and therefore impacts on material properties. This important properties of polyester synthases has therefore been targeted by various research groups to alter substrate specificity for the production of tailor-made biopolyesters. Random approaches as well as rational design were successfully applied to change the substrate specificity. The catalytic residues were found to play a role in substrate specificity of the class II polyester synthase from $P$. aeruginosa (Amara and Rehm, 2003). Localized semirandom mutagenesis has been used to alter substrate specificity of the class II polyester synthase from $P$. putida (Sheu and Lee, 2004). Recently, Tsuge et al. (Tsuge et al., 2004) found that the A510 of the C. necator polyester synthase is involved in substrate specificity.

The in vitro substrate specificities of $C$. necator and $A$. vinosum polyester synthases have been determined with analogs of varied chain length and branching, $\mathrm{OH}$ group position within the chain, and thioesters (Yuan et al., 2001). These data suggested that both polyester synthases are rather specific in vitro.

However, the substrate specificity of most of the polyester synthases was only estimated in vivo from cultivation experiments with precursor substrates provided as carbon source. The subsequent analysis of the chemical composition of the accumulated PHAs was used as an indication for the in vivo substrate specificity (Rehm, 2003). Since several bacteria such as pseudomonads harbor more than one polyester synthase gene and microbial metabolic diversity affects the provision of substrates this approach is only of limited value. The substrate range of polyester synthases was studied in recombinant $E$. coli using metabolic engineering to provide various 3-hydroxy fatty acid CoA thioester from fatty acids (Antonio et al., 2000; Dennis et al., 1998; Langenbach et al., 1997; Qi et al., 1997; Qi et al., 1998). These studies showed a rather broad substrate specificity, which was for example indicated by the ability of the class I polyester synthase from C. necator to accept also medium-chain-length 3hydroxy fatty acid CoA thioesters as substrate (Antonio et al., 2000; Dennis et al., 1998). These studies allowed for the first time the independent analysis of the substrate range of the two class II polyester synthases PhaC1 and $\mathrm{PhaC2}$ from $P$. aeruginosa, showing that polyester synthases display a similar substrate specificity and that 3-hydroxydecanoyl-CoA is the major substrate. The increasing number of natural and synthetic constituents identified in PHAs synthesized by bacteria further supports finding that synthase show an extremely broad substrate specificity (Rehm, 2003). Furthermore, this was demonstrated by the use of 3-mercaptopropionic acid as carbon source for $C$. necator, which resulted in the formation of a novel polyester, which is composed of 3- 
hydroxybutyric acid and 3-mecaptopropionic acid that is linked via thioester bonds (Lutke-Eversloh et al., 2001).

\section{Polyester inclusions: self-assembly and structure} Gerngross and Martin (Gerngross and Martin, 1995) were the first demonstrating in vitro synthesis of PHA and selfassembly of spherical granules by only using purified polyester synthase and substrate. This study clearly and ultimately defined that the polyester synthase possesses all the features required for self-organization into spherical particles.

In vivo formation of polyester particles

$\mathrm{PHA}$ biosynthesis starts in vivo as soon as the substrate, $(R)$-3-hydroxyacyl-CoA thioesters, is intracellularly provided. Low levels of the polyester synthase are constitutively produced and upon availability of substrate these enzymes begin to catalyze polymerization of high molecular weight polyester $(n>1000)$. The growing polyester chain, which remains covalently attached to the enzyme (Hezayen et al., 2002a), converts the initially soluble enzyme into an amphipathic molecule.

In the literature currently two models of PHA granule formation have been described: (i) the micelle model and (ii) the budding model (Fig. 5). Both models consider the defined location of the polyester synthase and to some extent the phasin protein on the surface of the granule. The micelle model is certainly supported by PHA granule formation in vitro and in the absence of membranes. However, first electron microscopy studies showing membrane-like material surrounding PHA granules in intact cells (Boatman, 1964; Dunlop and Robards, 1973; Jensen and Sicko, 1971; Wang and Lundgren, 1969) or isolated granules (Lundgren et al., 1964; Mayer et al., 1996) provided evidence for the budding model. In time course studies Tian and coworker (Tian et al., 2005c) showed that early stage granules are not randomly distributed in the cytoplasm and close to the inner cell membrane, as would be anticipated from the two models of granule formation. They found that emerging granules arose from only the center of the cell at unknown mediation elements. Localization of nascent granules close to the unknown mediation elements suggested a new model for PHA granule formation considering the unknown mediation elements as scaffolds, providing sites for the synthase to initiate granule formation. Dennis and coworker (Dennis et al., 2003) observed large structures $(35 \mathrm{~nm})$ on the surface of PHB-containing granules from $C$. necator cells using atomic force microscopy. They assumed that these structures might function as synthesis-degradation centers (Dennis et al., 2003).

Nevertheless, the above described observations were based on electron microscopy analysis using denatured samples. Recent fluorescence microscopy studies employing GFP-labeled polyester synthase, i.e. GFP was fused to the $\mathrm{N}$ terminus of class I and class II polyester synthases, respectively, without affecting PHA particle formation, enabled in vivo monitoring of PHA granule formation as well as subcellular localization (Peters and Rehm, 2005). In this study early stage granules were found to be localized to the cell poles suggesting that granule formation starts at the cell poles according to the budding model. Localization of granule formation was found to be dependent on nucleoid structure suggesting that nucleoid occlusion occurred (Peters and Rehm, 2005). Interestingly, this study led to the observation that small emerging granules are rapidly oscillating between the cell poles (Peters and Rehm, 2005) (A movie file associated with this article can be found, in the online version, at doi:10.1016/j.femsle.2005.05.027). This might play a role in equal distribution of storage materials between the daughter cells (Peters and Rehm, 2005).

The localization of emerging PHA granules at the cell poles was also confirmed by using Nile red staining of PHA granules as well as by $\mathrm{C}$ terminal fusion of a yellow fluorescent protein to a phasin, a structural protein noncovalently attached to granules, but not required for granule formation (Jendrossek, 2005; Schultheiss et

A

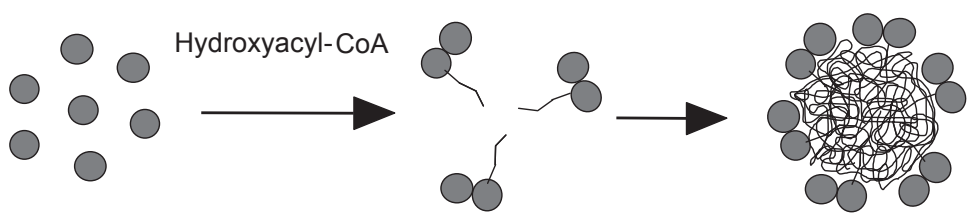

Soluble polyester synthase

Amphipathic polyester synthase

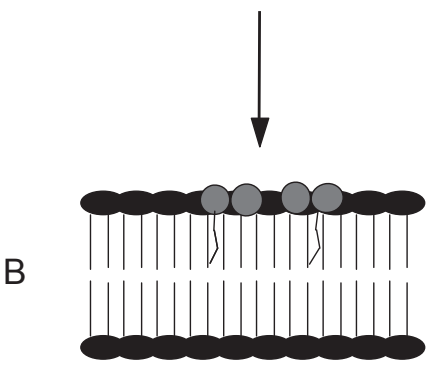

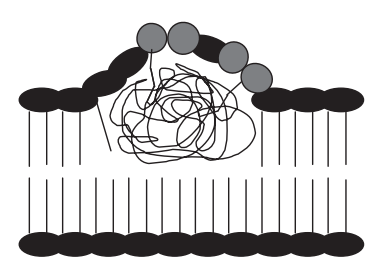

\section{Polyester particle}

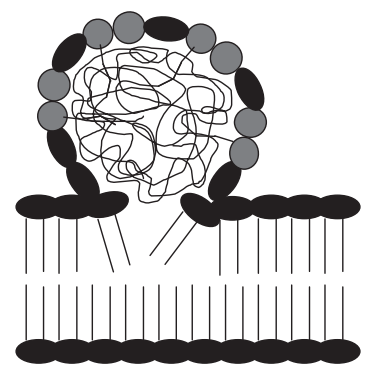

Fig. 5. Models of polyester granule formation. (A) Micelle model (also representing the in vitro formation in the absence of phospholipids and (B) budding model showing granule formation at the cytoplasmic membrane. 
al., 2005). Overall, these in vivo studies supported the budding model by localizing granule formation close to the cytoplasmic membrane at the cell poles.

In either model of granule formation, the polyester synthase is converted into an amphipathic molecule upon polyester chain synthesis and a self-assembly process occurs either in the membrane or in the cytosol (Fig. 5). Small water-insoluble and spherical inclusions are formed with an amorphous polyester core and polyester synthase covalently attached to the surface (Gerngross et al., 1993; Mayer and Hoppert, 1997) (Fig. 5). These PHA granules grow in size while the attached polyester synthases continuously convert precursor from the cytosol into constituents of the growing polyester chain. It is still unclear whether larger granules occur due to fusion events or whether simple increase in size based on continuous polymerization takes place. About 5-8 PHA granules are formed intracellularly comprising almost the entire cell volume, when maximum PHA accumulation is obtained (Steinbüchel et al., 1995). The PHA granules are surrounded by a phospholipid membrane (Griebel et al., 1968) with embedded or attached proteins (Stuart et al., 1998) composed of the polyester synthase (Gerngross et al., 1993; Liebergesell et al., 1994; Mayer et al., 1996; Valentin et al., 1998), the intracellular PHA depolymerase (Gao et al., 2001; Handrick et al., 2000; Saegusa et al., 2001; York et al., 2003), amphipathic phasin proteins (Jurasek and Marchessault, 2002; Pieper-Furst et al., 1995; Wieczorek et al., 1996; York et al., 2001a; York et al., 2001b), PHA-specific regulator proteins (Maehara et al., 2002; Pötter et al., 2004; Pötter et al., 2005; Prieto et al., 1999; York et al., 2002) and additional proteins (Klinke et al., 2000) with unknown function.

The intracellular depolymerases are required for mobilization of the reserve polyester and are attached to the granule surface. The $\mathrm{C}$ terminal domain is binding to the polyester core via hydrophobic interaction (Saegusa et al., 2001).

The phasin proteins play a role as structural proteins non-covalently attached to the polyester core of granules by their $\mathrm{N}$ terminal domain (Hanley et al., 1999). Phasins promote PHA biosynthesis and their copy number has impact on PHA granule size (Pötter et al., 2005; York et al., 2001a). Simulation of the kinetics of the self-assembly process showed that phasins impact on the kinetics of granule formation by reducing the lag phase (Jurasek and Marchessault, 2004). Recently, first crystals of a phasin protein from Aeromonas hydrophila were obtained (Zhao et al., 2006).

Various PHA-specific regulators such as $\mathrm{PhbR}$ from C. necator (Pötter et al., 2002; York et al., 2002), PhaF from pseudomonads (Hoffmann and Rehm, 2004, 2005; Prieto et al., 1999) and PhaR from Paracoccus denitrificans (Maehara et al., 1999; Maehara et al., 2002) were found to bind non-covalently to the PHA granules.

Additional proteins were found to be granuleassociated in pseudomonads, which function has not been clarified, yet. However, the expression of the respective genes is co-regulated with other PHA biosynthesis genes and these proteins (Phal, PhaD, PhaS) are considered as structural proteins also involved in biosynthesis and mobilization (Hoffmann and Rehm, 2004, 2005; Klinke et al., 2000; Prieto et al., 1999).

When PHA granules are heterologously produced in recombinant $E$. coli, a few specific $E$. coli proteins attach to the granule surface presumable functionally replacing the phasin proteins (unpublished data).

All of these non-covalently attached proteins are not essential for PHA granule formation, but serve various biological functions such as e.g. PHA granule structure, PHA biosynthesis gene regulation and PHA mobilization. However, only the covalently attached polyester synthases possess all the inherent properties required for PHA granule formation.

\section{Structure}

Proteins are embedded in or associated with a phospholipid monolayer surrounding the PHA core according to one model, whereas another model outlines a much more complex membrane structure with two phospholipid membranes (Rehm, 2003). NMR analysis provided evidence that water molecules are present in the core structure of the granules and that these molecules function as plasticizer (Barnard and Sanders, 1989). Thus the enzyme(s) responsible for PHA biosynthesis and consumption operate only on mobile hydrated material and that the solid granules characteristics of dried cells are partially artifactual.

The establishment of in vitro polyester synthesis using purified polyester synthases form various microorganism, such as e.g. from $C$. necator, $A$. vinosum, $P$. aeruginosa (PhaC1 and PhaC2) and P. oleovorans (PhaC1) (Jossek et al., 1998; Jossek and Steinbüchel, 1998; Liu and Steinbüchel, 2000; Muh et al., 1999; Qi et al., 2000; Rehm et al., 2001) provided a new tool to study the formation of macroscopic PHA granules. In vitro PHA synthesis was firstly achieved using recombinantly produced and purified C. necator polyester synthase (Gerngross and Martin, 1995). The granule formation occurred after only a few minutes when the substrate, $(R)$-3-hydroxybutyryl coenzyme $A$, was provided to the purified polyester synthase. These in vitro synthesized granules are spherical with diameters of up to $3 \mu \mathrm{m}$ and are larger than the respective native granules $(\sim 0.2 \mu \mathrm{m})$. This in vitro polymerization system yielded a PHB with a molecular mass $>10 \times 10^{6}$, exceeding ten-fold the mass of PHAs typically extracted from microorganisms. Interestingly, an increase in polyester synthase concentration resulted in a decrease of the weight average molar mass of the in vitro synthesized PHB (Gerngross and Martin, 1995). These observations were confirmed by in vivo studies, which revealed a dependency of the weight average molar mass from the amount of polyester synthase and which demonstrated that the in vitro synthesis studies are useful tools to simulate the in vivo situation (Sim et al., 1997). In vitro $\mathrm{PHB}$ synthesis was also obtained with purified class III polyester synthase from $A$. vinosum resulting in macroscopic PHB granules (Jossek and Steinbüchel, 1998). Interestingly, the rate of PHA synthesis in vitro was about 200-fold higher than in vivo. Various factors were investigated for their impact on in vitro PHB synthesis, and CoA was identified as a competitive inhibitor of the 
polyester synthase (Jossek et al., 1998; Muh et al., 1999). Thus coupled enzyme systems were developed to enable recycling of CoA and a low free CoA level (Jossek et al., 1998). CoA thioester synthesis requires hydrolysis of expensive ATP, and ATP regeneration using cheaper poly $(P)$ was successfully achieved using adenylate kinase and polyphosphate kinase.

The class II polyester synthase PhaC1 was recently purified from two pseudomonads and provision of 3-hydroxydecanoyl-CoA (Rehm et al., 1998) as substrate was sufficient for in vitro synthesis of poly(3hydroxydecanoate) (Qi et al., 2000; Rehm et al., 2001; Ren et al., 2000a). The specific activity of the $P$. aeruginosa synthase of $37 \mathrm{mU} \mathrm{mg}^{-1}$ was about 3000 -fold lower than the specific activity from the previously characterized class I and class III polyester synthases. Moreover, the specific activity of the purified class II polyester synthase was also about 20 -fold lower than the estimated specific activitiy of granule-bound polyester synthase (Kraak et al., 1997). CoA was also found as competitive inhibitor of the class II polyester synthase. A coupled enzyme system was developed using an acyl-CoA synthetase and the class II polyester synthase from $P$. aeruginosa that enabled recycling of $\mathrm{CoA}$ and first in vitro synthesis of quantitative amount of the homopolyester poly(3hydroxydecanoate). Quantification of the produced polymer and determination of the average weight molar mass of about $100000 \mathrm{~g} \mathrm{~mol}^{-1}$, allowed calculation of the number of polymer chains synthesized by a single polyester synthase molecule. These calculations revealed that one polyester synthase molecule synthesized 0.6 polymer chains, which indicated that no chain transfer reaction did occur (Qi et al., 2000). Interestingly, similar results were obtained from experiments with class I polyester synthase from C. necator (Gerngross and Martin, 1995), whereas class III polyester synthases showed a chain transfer (25 chains per PhaC/E-complex) during in vitro synthesis based on the calculation mentioned above (Jossek et al., 1998).

\section{In vivo substrate provision for polyester synthases}

The metabolic provision of 3-hydoxyacyl-CoA thioesters initiates the formation of PHA inclusions and strongly influences PHA composition. Thus the knowledge of precursor biosynthesis pathways should enable metabolic engineering aiming at tailor-made PHAs. In the last decade, the number of different PHAs with new constituents, varying composition and molecular weight, which show a broad range of material properties has significantly increased. The PHAs can be categorized into the two different classes based on their composition: (i) PHAs composed of short-chain length 3-hydroxy fatty acids (ranging from 3-5 carbon atoms) are represented by PHB produced from $C$. necator and (ii) PHAs composed of medium-chain length 3-hydroxy fatty acids produced by pseudomonads. The major biosynthesis pathways are summarized in Fig. 6.

\section{Short-chain length polyester biosynthesis}

The biosynthesis pathway of PHB has been studied in detail in R. eutropha (Peoples and Sinskey, 1989a, 1989b; Schubert et al., 1988; Slater et al., 1988). In this bacterium, the biosynthesis process is initiated by the condensation of two acetyl-CoA molecules to acetoacetyl-CoA catalyzed by the enzyme $\beta$-ketothiolase (EC 2.3.1.9). AcetoacetylCoA is then reduced to $(R)-3$-hydroxybutyryl-CoA by

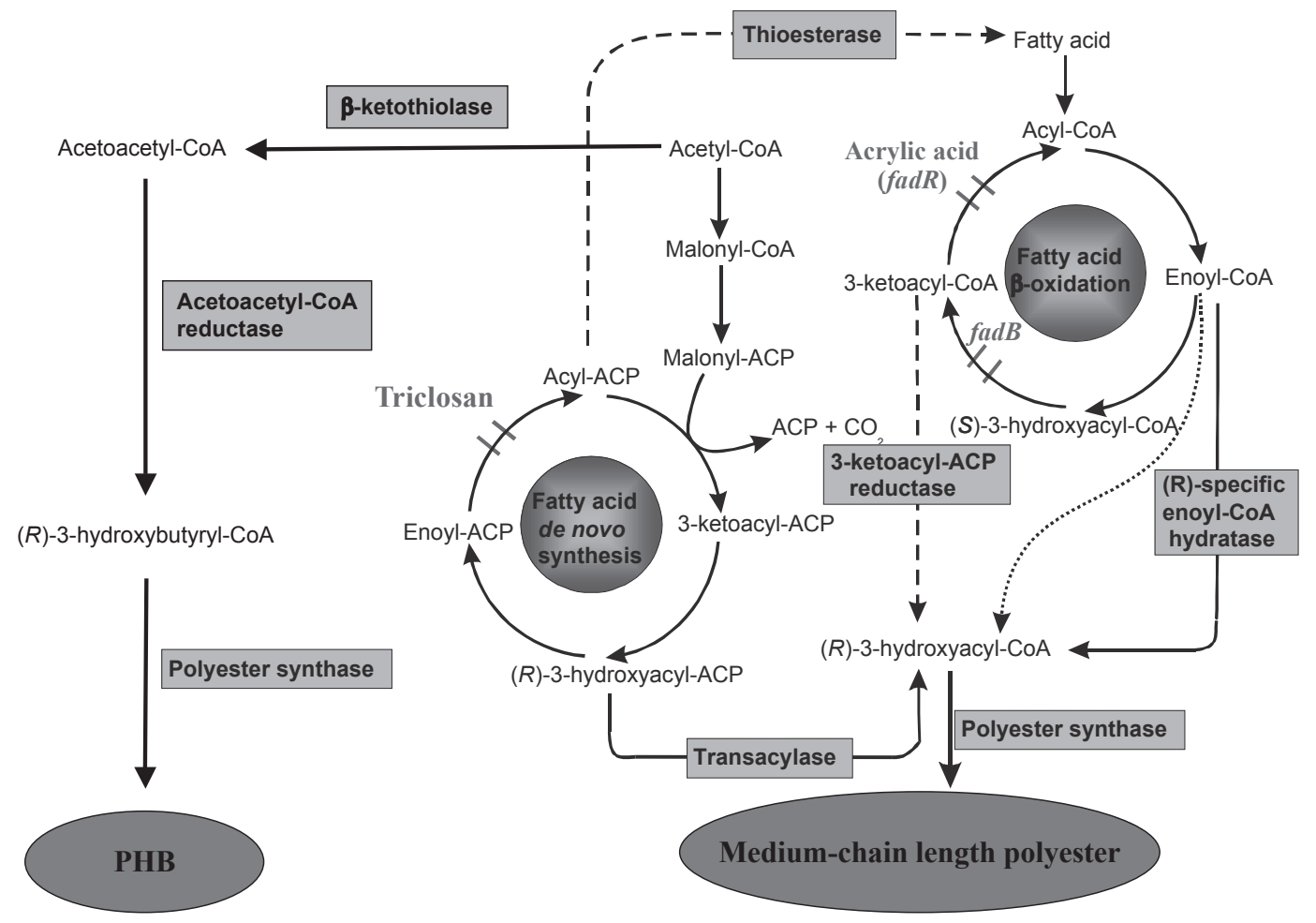

Fig. 6. Metabolic routes for polyester biosynthesis. 
the NADPH-dependent acetoacetyl-CoA reductase (EC 1.1.1.36). These enzymes have been found and studied in several PHB-accumulating bacteria.

\section{Medium-chain length polyester biosynthesis from non- related carbon sources}

Inhibition of fatty acid de novo biosynthesis suggested that the fatty acid de novo biosynthesis is involved in medium-chain length PHA synthesis, when non-related carbon sources such as gluconate were used. The phaG gene encoding a (R)-3-hydroxydecanoyl-ACP:CoA transacylase, which links fatty acid de novo biosynthesis with PHA biosynthesis, was identified in P. putida (Rehm et al., 1998). PhaG is only required for PHA synthesis when gluconate or other non-related carbon sources, which are oxidized to acetyl-CoA, are provided. AcetylCoA enters into the fatty acid de novo biosynthesis and intermediates are diverted to PHA biosynthesis. An isogenic phaG knock-out mutant of $P$. aeruginosa was constructed, which $\mathrm{PHA}_{\mathrm{MCL}}$ accumulation from gluconate was decreased to only $40 \%$ of wild type level, which was in contrast to the phaG-negative mutant of P. putida $\mathrm{PhaG}_{\mathrm{N}^{-}}$ 21 exhibiting only $5 \%$ of the wild type medium-chain length PHA content (Rehm et al., 1998). These data suggested that in $P$. aeruginosa alternative medium-chain length PHA biosynthesis pathways might be more emphasized than in P. putida. Recently, it was reported that RhIA plays a role not only in surfactant synthesis, but also in the production of polyhydroxyalkanoates by $P$. aeurginosa (Soberon-Chavez et al., 2005). Transcriptional analysis of phaG in $P$. putida was induced, when gluconate was used as carbon source. Transcription was repressed, when fatty acids were applied as carbon source (Hoffmann et al., 2000a, 2000b; Rehm et al., 1998). In addition to carbon source-dependent regulation of phaG evidence for nitrogen-dependent phaG transcription was obtained. Nitrogen starvation conditions resulted in an increased PhaG-mediated $\mathrm{PHA} \mathrm{MCL}_{\mathrm{M}}$ accumulation in nonPHA accumulating $P$. fragi (Fiedler et al., 2000). Further investigations indicated that $\mathrm{RpoN}$ is involved in phaG regulation and that $\mathrm{RpoN}$ seems to play a more global role in PHA biosynthesis gene regulation (Hoffmann and Rehm, 2004, 2005).

\section{The fatty acid $\beta$-oxidation pathway provides precursor from fatty acids}

Analysis of co-monomer composition of medium-chain length PHA proposed that medium-chain length PHA biosynthesis is closely related to the $\beta$-oxidation pathway, when fatty acids serve as related carbon source. The comonomers in medium-chain length PHA were identical to the substrate or shortened by 2,4 , or 6 carbon atoms if a straight chain fatty acid of 6 to 12 carbon atoms was used as carbon source (Huisman et al., 1989). The compositional analysis of PHAs accumulated by $P$. oleovorans cultivated on defined mixtures of medium-chain length alkanes and alkenes suggested that 3-hydroxyacylCoA intermediates of the $\beta$-oxidation pathway function as precursors for the PHA biosynthesis. PHA produced from $\left[1-{ }^{13} \mathrm{C}\right]$-labeled decanoate exhibited a specific ${ }^{13} \mathrm{C}$ enrichment of the 1-C atom, which was only represented in the 3-hydroxydecanoate methyl esters but not in the 3- hydroxyoctanaote and 3-hydroxyhexanoate methyl esters. The labeled $\mathrm{C}_{2}$-fragment is presumably removed in the first cycle of $\beta$-oxidation yielding unlabeled intermediates with a chain length of eight carbon atoms (Huijberts et al., 1994). These data support the suggestions that precursors for polymerization are generated through fatty acid $\beta$ oxidation of fatty acids. The $\beta$-oxidation pathway has been intensively investigated on the molecular and enzymatic level for $E$. coli but concerning pseudomonads only fad genes of the non-PHA accumulating $P$. fragi have been characterized. As the $\beta$-oxidation is a general metabolic pathway the results of $E$. coli might be transferred to pseudomonads. In this pathway fatty acids are activated by the acyl-CoA synthetase (fadD gene product) forming the corresponding acyl-CoA thioesters after uptake into the cell. These intermediates enter the $\beta$-oxidation cycle where they are finally degraded to acetyl-CoA by removal of $\mathrm{C}_{2}$ units. After reduction of acyl-CoA to trans-2,3-enoylCoA catalyzed by the acyl-CoA dehydrogenase (fadE gene product) the further conversion is catalyzed by the $\beta$-oxidation multi enzyme complex encoded by the fadBA operon. There are four enzymatic activities associated with this $\alpha_{2} \beta_{2}$ protein complex. On the large $\alpha$-subunit encoded by $\operatorname{fad} B$ gene the enoyl-CoA hydratase and the cis- $\Delta^{3}$ trans- $\Delta^{2}$-enoyl-CoA-isomerase share one active binding site, whereas the 3-hydroxyacyl-CoA dehydrogenase activity has a separate active center. The 3-hydroxyacylCoA epimerase function of the multi enzyme complex is presumably due to the stereoselectivity of the enoyl-CoA hydratase catalyzing the reversible hydration reaction of enoyl-CoA to $(S)$ - and $(R)$-3-hydroxyacyl-CoAs, whereas the $(R)$-enantiomer represents only a minor product of the overall hydration reaction. There is no experimental evidence for an enoyl-CoA hydratase-independent epimerase activity in E. coli, which has been postulated in various publications (Yang and Elzinga, 1993). The 3ketoacyl-CoA thiolase is encoded by the fadA gene, which gene product represents the smaller $\beta$-subunit. The fatty acid $\beta$-oxidation intermediates which namely trans-2,3enoyl-CoA, (S)-3-hydroxyacyl-CoA and 3-ketoacyl-CoA are supposed to be precursors for the PHA biosynthesis. Since $(R)$-3-hydroxyacyl-CoA thioesters (C6 to C14) serve as substrates for class II polyester synthases intermediates of $\beta$-oxidation cannot be directly used for medium-chain length PHA biosynthesis. Therefore, enzymes like the $(R)$-specific enoyl-CoA hydratase, hydroxyacyl-CoA epimerase, and $\beta$-ketoacyl-CoA reductase have been postulated connecting the $\beta$-oxidation pathway with the medium-chain length PHA biosynthesis.

3-Hydroxyacyl-CoA epimerase. The 3-hydroxyacylCoA epimerase is supposed to catalyze the conversion of the (S)-3-hydroxyacyl-CoA to the corresponding $(R)$-enantiomer. So far, a specific 3-hydroxyacyl-CoA epimerase linking the $\beta$-oxidation pathway with the medium-chain length PHA biosynthesis has not been discovered, yet. However, the $\beta$-oxidation multi enzyme complex of $E$. coli exhibits an epimerase function, which results from the stereospecificity of the enoyl-CoA hydratase leading to some extent to the formation of $(R)$ 3-hydroxyacyl-CoA (Yang and Elzinga, 1993). Therefore, it should be possible to derive (R)-3-hydroxyacyl-CoA in 
sufficient amounts as precursor for medium-chain length PHA biosynthesis, when the $\beta$-oxidation pathway would be impaired, employing genetic approaches or enzyme inhibitors in order to generate a pool of the $(S)$ - and the $(R)$-enantiomer of 3-hydroxyacyl-CoA. The polymerization reaction catalyzed by a heterologous polyester synthase might than remove the $(R)$-enantiomer, which would shift the equilibrium towards formation of $(R)$-3-hydroxyacylCoA. The production of medium-chain length PHA in recombinant $E$. coli was achieved for the first time, when class II polyester synthase genes (phaC1 and phaC2) from $P$. aeruginosa were heterologously expressed in an E. coli fadB mutant (Langenbach et al., 1997). Cultivation on LB medium containing decanoate as carbon source resulted in the accumulation of medium-chain length PHA, but no significant accumulation of medium-chain length PHA was observed when $E$. coli with wild type $\beta$ oxidation pathway was used (Langenbach et al., 1997; Qi et al., 1997).

Alternative fatty acid $\beta$-oxidation enzymes. The $\mathrm{YfcX}$, with significant similarity to the large subunit of multifunctional $\beta$-oxidation enzymes was found to be required for medium-chain length PHA production in $E$. coli fadB mutant. Plasmid-based expression of $y f c X$ in the $\operatorname{FadB}(-)$ $\mathrm{YfcX}(-) \quad \mathrm{PhaC}(+)$ strain restores polymer formation. YfcX has been shown to be a multifunctional enzyme that minimally encodes hydratase and dehydrogenase activities. Results of insertional inactivation studies and enzyme activity analyses suggest a role for $\mathrm{YfcX}$ in PHA monomer unit formation in recombinant $E$. coli fadB mutant strains (Snell et al., 2002).

Recently, it has been shown that MaoC, a new enoyl-CoA hydratase, is also involved in supplying $(R)$ 3-hydroxyacyl-CoA from the $\beta$-oxidation pathway to PHA biosynthetic pathway in the $f a d B$ mutant $E$. coli strain (Park and Lee, 2003).

Inhibition of fatty acid $\beta$-oxidation. Cultivation of several E. coli wild type strains expressing the phaC1 gene of $P$. aeruginosa on LB medium with decanoate as carbon source and in presence of acrylic acid as an inhibitor of the $\beta$-oxidation pathway resulted in strong mediumchain length PHA production contributing to 20-30\% of $\mathrm{CDW}$, whereas an E. coli fadR mutant showed the strongest medium-chain length PHA accumulation of about $60 \%$ of CDW (Qi et al., 1998). In this mutant the $\beta$-oxidation is derepressed by the mutation of the fadR gene encoding a repressor. This led to strong production of the $\beta$-oxidation multi enzyme complex and to inhibition of the final enzymatic step of the $\beta$-oxidation cycle by acrylic acid resulting in strong medium-chain length PHA accumulation (Qi et al., 1998). Accordingly, it was also possible to mediate medium-chain length PHA accumulation in a recombinant $P$. fragi strain as well as in an PHB-negative Ralstonia eutropha strain by applying acrylic acid and expressing phaC1 from $P$. aeruginosa (Fiedler et al., 2002; Green et al., 2002). Thus, acrylic acid might be a useful tool to divert intermediates of $\beta$ oxidation to medium-chain length PHA biosynthesis even in non-PHA accumulating bacteria.
Fatty acid $\beta$-oxidation enzymes of pseudomonads. Since various pseudomonads accumulate large amounts of medium-chain length PHAfrom fatty acids, we investigated the $\beta$-oxidation pathway of $P$. oleovorans, in order to evaluate whether this pathway directly provides precursor for medium-chain length PHA synthesis or if additional PHA biosynthesis enzymes are required. The fadBA genes from $P$. oleovorans were cloned and functionally co-expressed with a polyester synthase gene in various $E$. coli strains cultivated on fatty acids. The fadBA genes did not enable medium-chain length PHA synthesis in $E$. coli, suggesting that $P$. oleovorans FadBA has no inherent property favoring medium-chain length PHA synthesis (Fiedler et al., 2002). These data were consistent with the discovery of $(R)$-specific enoyl-CoA hydratases in pseudomonads, which catalyze the conversion of enoylCoA to $(R)$-3-hydroxylacyl-CoA.

(R)-Specific enoyl-CoA hydratases. Trans-2,3-enoyl-CoA is converted into $(R)$-3-hydroxyacyl-CoA by stereospecific addition of $\mathrm{H}_{2} \mathrm{O}$ to the double bond catalyzed by $(R)$ specific enoyl-CoA hydratases. The first $(R)$-specific enoyl-CoA hydratase was cloned and characterized from Aeromonas punctata, which accumulated a random copolymer of 3-hydroxybutyrate and 3-hydroxyhexanoate when grown on even-numbered fatty acids or oils. The $(R)$-specific enoyl-CoA hydratase is encoded by the gene phaJ and localized at the pha locus downstream of a phasin gene and the polyester synthase gene. The heterologous expression of the Aeromonas caviae phaJ and phaC genes in PHA- and PHB-negative host strains like $C$. necator $\mathrm{PHB}^{-4}$ resulted in accumulation of the respective co-polymer. These results indicated that $(R)$ specific enoyl-CoA hydratases divert intermediates of $\beta$-oxidation to PHA biosynthesis. The in vitro enzymatic activity was determined by conversion of 3-hydroxybutyrylCoA as substrate (Fukui and Doi, 1997). Two genes encoding for two $(R)$-specific enoyl-CoA hydratases which exhibit different substrate specificities were identified from $P$. aeruginosa. For both enoyl-CoA hydratases an in vivo substrate range of $\mathrm{C} 4$ to $\mathrm{C} 12$ was determined (Tsuge et al., 2000). Recently, we cloned genes from $P$. putida and $P$. oleovorans which exhibited high homology to the phaJ1 gene of $P$. aeruginosa indicating that the $(R)$-specific enoyl-CoA hydratases represent a general principle in medium-chain length PHA synthesis via fatty acid $\beta$-oxidation (Fiedler et al., 2002).

$\beta$-Ketoacyl-CoA reductase. Acetoacetyl-CoA reductases catalyze the second step in the PHB biosynthesis pathway by converting acetoacetyl-CoA to $(R)$-3-hydroxybutyrylCoA while oxidizing of NADPH or NADH. However, a specific $\beta$-ketoacyl-CoA reductase mediating mediumchain length PHA biosynthesis via the $\beta$-oxidation pathway in wild type strains is still unknown. The effect of heterologously expressed genes encoding a acetoacetylCoA reductase $(\mathrm{PhbB})$ or a 3-ketoacyl-ACP reductase (FabG) on the accumulation and composition of PHA has been investigated in various recombinant strains. The acetoacetyl-CoA reductase and the class I polyester synthase from $C$. necator were co-expressed in $E$. coli, 
Klebsiella aerogenes and in PHA-negative mutants of $P$. putida and C. necator, respectively. Expression in E. coli resulted in PHB formation regardless of the substrate, whereas strains of $K$. aerogenes, $P$. putida, and $C$. necator accumulated a co-polymer of 3-hydroxybutyrate and 3hydroxyhexanoate during growth on even numbered fatty acids. The provision of 3-hydroxybutyryl-CoA and 3hydroxyhexanoyl-CoA in C. necator was presumably due to channeling of the 3-ketoacyl-CoA intermediates of the $\beta$-oxidation to PHA biosynthesis by functional expression of $p h b B$ (Dennis et al., 1998). In a second study the acetoacetyl-CoA reductase $(p h b B)$ from $C$. necator was co-expressed with a class II polyester synthase (phaC2) from $P$. oleovorans in an $E$. coli mutant defective in $\beta$ oxidation ( $\operatorname{fad} R \operatorname{fad} A)$. In this strain the $\beta$-oxidation enzymes are constitutively expressed but the degradation of $\beta$-ketoacyl-CoA is blocked causing accumulation of 3ketoacyl-CoA in the cell. The introduction of acetoacetylCoA reductase caused an increase in medium-chain length PHA accumulation from about $15 \%$ to $20 \%$ of cellular dry weight as well as a shift in monomer composition to a higher ratio of monomers with shorter chain length (Ren et al., 2000b).

The overproduction of the 3-ketoacyl-ACP reductase (FabG) from E. coli and heterologous expression of the class I polyester synthase gene from $A$. punctata enabled recombinant $E$. coli strains to synthesize $\mathrm{PHA}$ contributing to about $8 \%$ of CDW, when dodecanoate was used as sole carbon source. The co-polymer was composed of $84 \mathrm{~mol} \%$ 3-hydroxybutyrate and $14 \mathrm{~mol} \%$ 3-hydroxyyhexanoate. When the class II polyester synthase from Pseudomonas sp. 61-3 gene was applied a polymer was obtained which was composed of $12 \mathrm{~mol} \%$ 3-hydroxyhexanoate, $80 \mathrm{~mol} \%$ 3-hydroxyoctanoate, and $8 \mathrm{~mol} \%$ 3-hydroxydecanoate. These data indicate that E. coli FabG exhibits a broad substrate specificity not only for ACP intermediates but also for $\mathrm{CoA}$ thioesters comprising chain lengths ranging from C4 to C10 (Taguchi et al., 1999).

\section{Engineered medium-chain length PHA biosynthesis} pathways including the fatty acid $\beta$-oxidation and the fatty acid de novo biosynthesis

Thioesterase. Coexpression of the cytosolic thioesterase I gene teas with a polyester synthase encoding gene in E. coli ( $\mathrm{fadB}, \mathrm{fadR}$ ) causes synthesis of small amounts of PHA mainly composed of 3-hydroxyoctanoate from gluconate as carbon source (Klinke et al., 1999). These data indicated that the fatty acid de novo synthesis as well as the $\beta$-oxidation pathway were involved. In another study the acyl-ACP thioesterase from the plant Umbellularia californica, which strongly prefers the lauroyl-ACP thioester instead of the corresponding CoA thioester, in order to efficiently establish a new metabolic link between medium-chain length PHA synthesis and fatty acid de novo biosynthesis. Coexpression of this acyl-ACP thioesterase gene with a class II polyester synthase gene in E. coli led to medium-chain length PHA accumulation from non-related carbon sources such as gluconate, but requiring an impaired $\beta$-oxidation pathway. Thus medium-chain length PHA biosynthesis from nonrelated carbon sources was established, releasing fatty acids from ACP intermediates of the fatty acid de novo biosynthesis by the activity of the acyl-ACP thioesterase, which were then activated to CoA thioesters employing a truncated fatty acid $\beta$-oxidation pathway (Langenbach et al., 1997; Qi et al., 1997).

\section{Production of tailor-made biopolyester nanoparticles and potential applications}

In the last decade the molecular biology and physiology of the bacterial biopolyester synthesis has been extensively studied (see above). Previous research activities were mainly aiming at the biotechnological production of the extracted and semi-crystalline thermoplastic polyester materials. Only recently it has been recognized that the intracellular polyester inclusions or derived from in vitro synthesis can be considered as natural bionanoparticles. These spherical nano- and submicroparticles are currently explored with respect to their commercial potential. Bionanoparticles can be conceived as shell-core particles with a hydrophobic polyester core surrounded by phospholipids and specific proteins constituting the shell. Numerous metabolic tools are available to control the polyester composition and thereby the material properties of the bionanoparticle core. Only recently, knowledge about the topology of particle surface attached proteins as well as the biogenesis i.e. the molecular mechanism of self-assembly of polyester particles has been gained. Recently, the fusion of a functional protein (GFP) to different polyester synthase has been published, which was not affecting bionanoparticle formation inside the bacterial cell (Peters and Rehm, 2005). The GFP was displayed at the particle surface (Fig. 7). The size of the particles has been shown to be dependent on attached proteins as well as the cell division machinery. Particle sizes with an average diameter ranging from 50 to $500 \mathrm{~nm}$ have been already obtained. In summary, the core composition, the surface functionality and the size of these bionanoparticles can be highly controlled and harnessed by a biotechnological production process.

The design of the nanoparticles should be achievable by in vivo biosynthesis of polyester particles in recombinant Escherichia coli (controlling the expression of genes, which encode particle biosynthesis/biogenesis relevant proteins, and genes, which encode fusion proteins of the aforementioned proteins) as well as in vitro using purified enzymes/proteins and/or the respective fusion proteins relevant for polyester particle biogenesis. More design space could be achieved by further processing of the isolated particles with respect to replacement of non-covalently surface-attached biomolecules with surfactants, phospholipids or proteins as well as by covalent cross-linking of biomolecules to the particle surface. Nanoparticles with surface areas constituting of $1-100 \%$ of protein (engineered protein) or $0-99 \%$ of phospholipids or other relevant amphipathic molecules could be generated. There is commercial interest in exploiting the unique potential of designed biogenic polyester particles suitable for e.g. protein production, bioseparation, drug delivery and vaccine design. Recent publications were exemplifying the application potential of these bioparticles in protein production (Banki et al., 2005), enzyme immobilization (Peters and Rehm, 2006), 

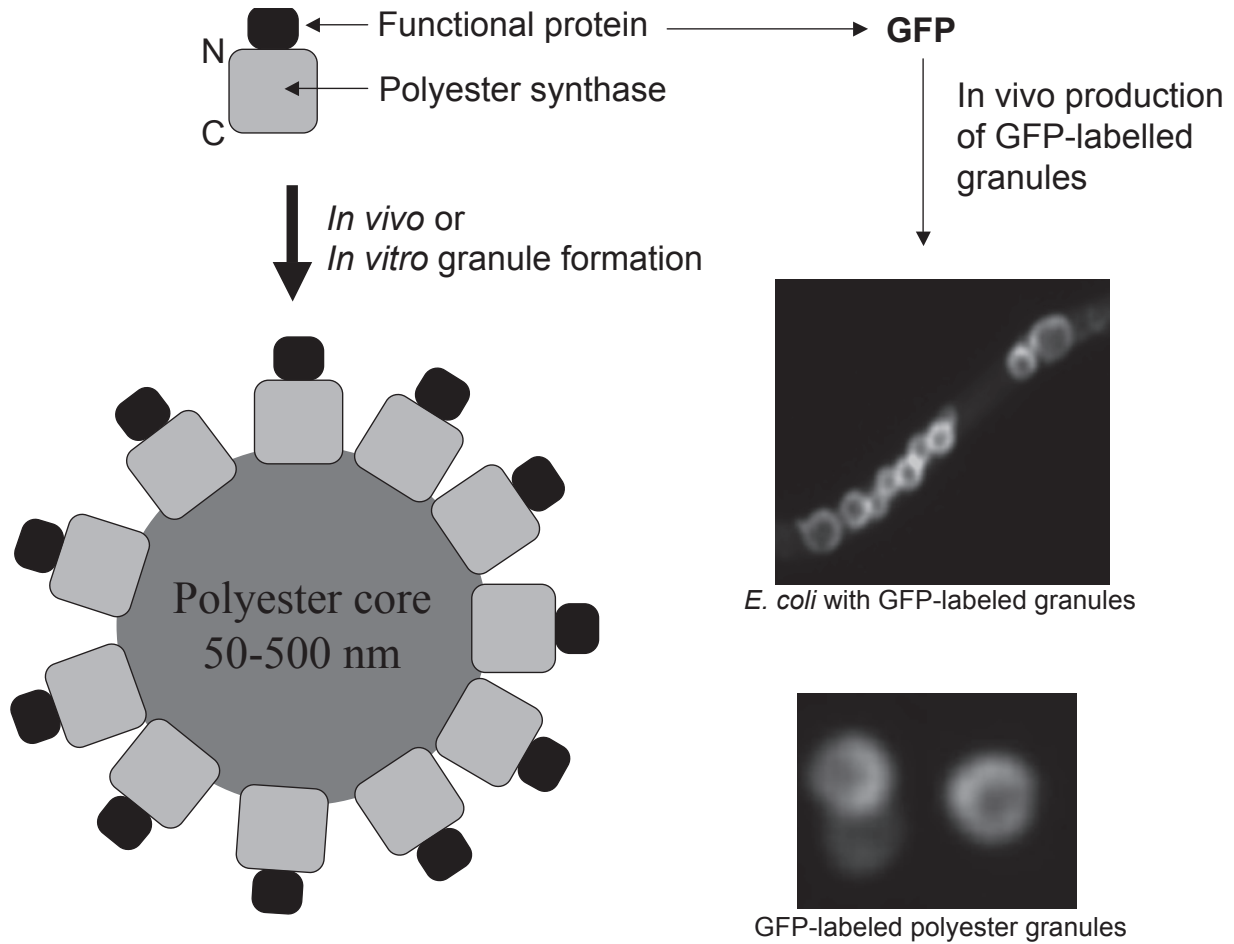

Fig. 7. Functionalization of polyester particles.

affinity purification (Brockelbank et al., 2006) as well as in diagnostics using bioparticle display of functional eukaryotic proteins in combinantion with fluorescence activated cell sorting (Bäckström et al., 2006). Patents have been filed considering the use of biopolyester particles encapsulating a drug during in vitro formation and for the general ex vivo use of biotechnologically produced functionalized biopolyester particles, which suggests a commercial potential of these naturally occurring nanostructures.

\section{Conclusions}

Biosynthesis pathways leading to the formation of a variety of biopolyesters composed of different sets of constituents have been extensively investigated and applied for metabolic engineering in order to obtain tailormade biopolymers. Random and rational approaches were successfully implemented to engineer biosynthesis proteins towards the production of novel tailor-made biopolyester. Effort has been undertaken to optimize the overall production process to reduce the price of these biodegradable biopolyesters making them competitive to oil-based polymers. Recent studies shed light into the molecular processes involved in formation of biopolyester inclusions inside the bacterial cell. However, the recognition of these nano-sized inclusions as nanoparticles, which can be functionalized to suit certain applications, occurred only very recently. Intracellular inclusion are increasingly identified as valuable nanostructures for bionanotechnology. A few companies already screen microorganisms from various habitats regarding their potential to produce intracellular nanostructures. Thus harnessing the commercial potential of nanostructures produced by microorganisms has become increasingly important. These approaches particularly aim at medical applications such as drug delivery or vaccine development utilizing the implied design space and the inherent biocompatibility.

\section{Acknowledgments}

The author thanks past and present members of his research group for contributions helping to understand important aspects of biopolyester synthesis. Work on the polyester synthases in my laboratory has been mainly supported by grants from Industry, Massey University, Deutsche Forschungsgemeinschaft and fellowships from the Deutsche Akademische Austauschdienst.

\section{References}

Addison, C.J., Chu, S.H., and Reusch, R.N. (2004). Polyhydroxybutyrate-enhanced transformation of logphase Escherichia coli. Biotechniques 37, 376-378, 380, 382.

Amara, A.A., Steinbüchel, A., and Rehm, B.H.A. (2002). In vivo evolution of the Aeromonas punctata polyhydroxyalkanoate (PHA) synthase: isolation and characterization of modified PHA synthases with enhanced activity. Appl. Microbiol. Biotechnol. 59, 477482.

Amara, A.A., and Rehm, B.H.A. (2003). Replacement of the catalytic nucleophile cysteine-296 by serine in class Il polyhydroxyalkanoate synthase from Pseudomonas aeruginosa-mediated synthesis of a new polyester: identification of catalytic residues. Biochem. J. 374, 413-421.

Anderson, A.J., Haywood, G.W., and Dawes, E.A. (1990). Biosynthesis and composition of bacterial 
poly(hydroxyalkanoates). Int. J. Biol. Macromol. 12, 102-105.

Antonio, R.V., Steinbüchel, A., and Rehm, B.H.A. (2000). Analysis of in vivo substrate specificity of the PHA synthase from Ralstonia eutropha: formation of novel copolyesters in recombinant Escherichia coli. FEMS Microbiol. Lett. 182, 111-117.

Bäckström, B. T., Brockelbank, J.A., and Rehm, B.H.A. (2006). Recombinant Escherichia coli produces tailor-made biopolyester granules for applications in fluorescence activated cell sorting: functional display of the mouse interleukin 2 and myelin oligodendrocyte glycoprotein. BMC Biotechnology, in press.

Baliga, N.S., Bonneau, R., Facciotti, M.T., Pan, M., Glusman, G., Deutsch, E.W., Shannon, P., Chiu, Y., Weng, R.S., Gan, R.R., Hung, P., Date, S.V., Marcotte, E., Hood, L., and Ng, W.V. (2004). Genome sequence of Haloarcula marismortui: a halophilic archaeon from the Dead Sea. Genome Res. 14, 2221-2234.

Banki, M.R., Gerngross, T.U., and Wood, D.W. (2005). Novel and economical purification of recombinant proteins: intein-mediated protein purification using in vivo polyhydroxybutyrate (PHB) matrix association. Protein Sci. 14, 1387-1395.

Barnard, G.C., McCool, J.D., Wood, D.W., and Gerngross, T.U. (2005). Integrated recombinant protein expression and purification platform based on Ralstonia eutropha. Appl. Environ. Microbiol. 71, 5735-5742.

Barnard, G.N., and Sanders, J.K. (1989). The poly-betahydroxybutyrate granule in vivo. A new insight based on NMR spectroscopy of whole cells. J. Biol. Chem. 264, 3286-3291.

Boatman, E.S. (1964). Observations on the fine structure of spheroplasts of Rhodospirillum rubrum. J. Cell Biol. 20, 297-311.

Brandl, H., Gross, R.A., Lenz, R.W., and Fuller, R.C. (1990). Plastics from bacteria and for bacteria: poly(beta-hydroxyalkanoates)as natural, biocompatible, and biodegradable polyesters. Adv. Biochem. Eng. Biotechnol. 41, 77-93.

Brockelbank, J.A., Peters, V., and Rehm, B.H.A. (2006). Recombinant Escherichia coli produces ZZ domain displaying biopolyester granules suitable for IgG purification. Appl. Environ. Microbiol. 72, 7394-7397.

Cuff, J.A., and Barton, G.J. (2000). Application of multiple sequence alignment profiles to improve protein secondary structure prediction. Proteins 40, 502-511.

Das, S., and Reusch, R.N. (1999). Gating kinetics of E. coli poly-3-hydroxybutyrate/polyphosphate channels in planar bilayer membranes. J. Membr. Biol. 170, 135145.

Das, S., and Reusch, R.N. (2001). pH regulates cation selectivity of poly-(R)-3-hydroxybutyrate/polyphosphate channels from E. coli in planar lipid bilayers. Biochemistry 40, 2075-2079.

Das, S., Seebach, D., and Reusch, R.N. (2002). Differential effects of temperature on $E$. coli and synthetic polyhydroxybutyrate/polyphosphate channels. Biochemistry 41, 5307-5312.

Dennis, D., McCoy, M., Stangl, A., Valentin, H.E., and Wu, Z. (1998). Formation of poly(3-hydroxybutyrate-co- 3-hydroxyhexanoate) by PHA synthase from Ralstonia eutropha. J. Biotechnol. 64, 177-186.

Dennis, D., Liebig, C., Holley, T., Thomas, K.S., Khosla, A., Wilson, D., and Augustine, B. (2003). Preliminary analysis of polyhydroxyalkanoate inclusions using atomic force microscopy. FEMS Microbiol. Lett. 226, 113-119.

Dunlop, W.F., and Robards, A.W. (1973). Ultrastructural study of poly- -hydroxybutyrate granules from Bacillus cereus. J. Bacteriol. 114, 1271-1280.

Fiedler, S., Steinbüchel, A., and Rehm, B.H.A. (2000). PhaG-mediated synthesis of Poly(3-hydroxyalkanoates) consisting of medium-chain-length constituents from nonrelated carbon sources in recombinant Pseudomonas fragi. Appl. Environ. Microbiol. 66, 21172124.

Fiedler, S., Steinbüchel, A., and Rehm, B.H.A. (2002). The role of the fatty acid beta-oxidation multienzyme complex from Pseudomonas oleovorans in polyhydroxyalkanoate biosynthesis: molecular characterization of the fadBA operon from $\mathrm{P}$. oleovorans and of the enoyl-CoA hydratase genes phaJ from P. oleovorans and Pseudomonas putida. Arch. Microbiol. 178, 149-160.

Fischer, H., Erdmann, S., and Holler, E. (1989). An unusual polyanion from Physarum polycephalum that inhibits homologous DNA polymerase alpha in vitro. Biochemistry 28, 5219-5226.

Fukui, T., and Doi, Y. (1997). Cloning and analysis of the poly(3-hydroxybutyrate-co-3-hydroxyhexanoate) biosynthesis genes of Aeromonas caviae. J. Bacteriol. 179, 4821-4830.

Gao, D., Maehara, A., Yamane, T., and Ueda, S. (2001). Identification of the intracellular polyhydroxyalkanoate depolymerase gene of Paracoccus denitrificans and some properties of the gene product. FEMS Microbiol. Lett. 196, 159-164.

Gerngross, T.U., Reilly, P., Stubbe, J., Sinskey, A.J., and Peoples, O.P. (1993). Immunocytochemical analysis of poly-beta-hydroxybutyrate (PHB) synthase in Alcaligenes eutrophus $\mathrm{H} 16$, localization of the synthase enzyme at the surface of PHB granules. J. Bacteriol. 175, 5289-5293.

Gerngross, T.U., Snell, K.D., Peoples, O.P., Sinskey, A.J., Csuhai, E., Masamune, S., and Stubbe, J. (1994). Overexpression and purification of the soluble polyhydroxyalkanoate synthase from Alcaligenes eutrophus: evidence for a required posttranslational modification for catalytic activity. Biochemistry 33, 9311-9320.

Gerngross, T.U., and Martin, D.P. (1995). Enzymecatalyzed synthesis of poly[(R)-(-)-3-hydroxybutyrate]: formation of macroscopic granules in vitro. Proc. Natl. Acad. Sci. USA 92, 6279-6283.

Green, P.R., Kemper, J., Schechtman, L., Guo, L., Satkowski, M., Fiedler, S., Steinbüchel, A., and Rehm, B.H.A. (2002). Formation of short chain length/medium chain length polyhydroxyalkanoate copolymers by fatty acid beta-oxidation inhibited Ralstonia eutropha. Biomacromolecules 3, 208-213.

Griebel, R., Smith, Z., and Merrick, J.M. (1968). Metabolism of poly-beta-hydroxybutyrate. I. Purification, 
composition, and properties of native poly-betahydroxybutyrate granules from Bacillus megaterium. Biochemistry 7, 3676-3681.

Griebel, R.J., and Merrick, J.M. (1971). Metabolism of poly-hydroxybutyrate: effect of mild alkaline extraction on native poly- -hydroxybutyrate granules. J. Bacteriol. 108, 782-789.

Handrick, R., Reinhardt, S., and Jendrossek, D. (2000). Mobilization of poly(3-hydroxybutyrate) in Ralstonia eutropha. J. Bacteriol. 182, 5916-5918.

Hanley, S.Z., Pappin, D.J., Rahman, D., White, A.J., Elborough, K.M., and Slabas, A.R. (1999). Re-evaluation of the primary structure of Ralstonia eutropha phasin and implications for polyhydroxyalkanoic acid granule binding. FEBS Lett. 447, 99-105.

Hezayen, F.F., Rehm, B.H.A., Eberhardt, R., and Steinbüchel, A. (2000). Polymer production by two newly isolated extremely halophilic archaea: application of a novel corrosion-resistant bioreactor. Appl. Microbiol. Biotechnol. 54, 319-325.

Hezayen, F.F., Steinbüchel, A., and Rehm, B.H.A. (2002a). Biochemical and enzymological properties of the polyhydroxybutyrate synthase from the extremely halophilic archaeon strain 56. Arch. Biochem. Biophys. 403, 284-291.

Hezayen, F.F., Tindall, B.J., Steinbüchel, A., and Rehm, B.H.A. (2002b). Characterization of a novel halophilic archaeon, Halobiforma haloterrestris gen. nov., sp. nov., and transfer of Natronobacterium nitratireducens to Halobiforma nitratireducens comb. nov. Int. J. Syst. Evol. Microbiol. 52, 2271-2280.

Hoffmann, N., Steinbüchel, A., and Rehm, B.H.A. (2000a). Homologous functional expression of cryptic phaG from Pseudomonas oleovorans establishes the transacylasemediated polyhydroxyalkanoate biosynthetic pathway. Appl. Microbiol. Biotechnol. 54, 665-670.

Hoffmann, N., Steinbüchel, A., and Rehm, B.H.A. (2000b). The Pseudomonas aeruginosa phaG gene product is involved in the synthesis of polyhydroxyalkanoic acid consisting of medium-chain-length constituents from non-related carbon sources. FEMS Microbiol. Lett. 184, 253-259.

Hoffmann, N., and Rehm, B.H.A. (2004). Regulation of polyhydroxyalkanoate biosynthesis in Pseudomonas putida and Pseudomonas aeruginosa. FEMS Microbiol. Lett. 237, 1-7.

Hoffmann, N., and Rehm, B.H.A. (2005). Nitrogendependent regulation of medium-chain length polyhydroxyalkanoate biosynthesis genes in pseudomonads. Biotechnol. Lett. 27, 279-282.

Hoppensack, A., Rehm, B.H.A., and Steinbüchel, A. (1999). Analysis of 4-phosphopantetheinylation of polyhydroxybutyrate synthase from Ralstonia eutropha: generation of beta-alanine auxotrophic Tn5 mutants and cloning of the panD gene region. J. Bacteriol. 181, 1429-1435.

Huang, R., and Reusch, R.N. (1996). Poly(3hydroxybutyrate) is associated with specific proteins in the cytoplasm and membranes of Escherichia coli. J. Biol. Chem. 271, 22196-22202.

Huijberts, G.N., de Rijk, T.C., de Waard, P., and Eggink, G. (1994). 13C nuclear magnetic resonance studies of Pseudomonas putida fatty acid metabolic routes involved in poly(3-hydroxyalkanoate) synthesis. J. Bacteriol. 176, 1661-1666.

Huisman, G.W., de Leeuw, O., Eggink, G., and Witholt, B. (1989). Synthesis of poly-3-hydroxyalkanoates is a common feature of fluorescent pseudomonads. Appl. Environ. Microbiol. 55, 1949-1954.

Jendrossek, D. (2005). Fluorescence microscopical investigation of poly(3-hydroxybutyrate) granule formation in bacteria. Biomacromolecules 6, 598-603.

Jensen, T.E., and Sicko, L.M. (1971). Fine structure of poly-beta-hydroxybutyric acid granules in a blue-green alga, Chlorogloea fritschii. J. Bacteriol. 106, 683-686.

Jia, Y., Kappock, T.J., Frick, T., Sinskey, A.J., and Stubbe, J. (2000). Lipases provide a new mechanistic model for polyhydroxybutyrate (PHB) synthases: characterization of the functional residues in Chromatium vinosum PHB synthase. Biochemistry 39, 3927-3936.

Jia, Y., Yuan, W., Wodzinska, J., Park, C., Sinskey, A.J., and Stubbe, J. (2001). Mechanistic studies on class I polyhydroxybutyrate (PHB) synthase from Ralstonia eutropha: class I and III synthases share a similar catalytic mechanism. Biochemistry 40, 1011-1019.

Jossek, R., Reichelt, R., and Steinbüchel, A. (1998). In vitro biosynthesis of poly(3-hydroxybutyric acid) by using purified poly(hydroxyalkanoic acid) synthase of Chromatium vinosum. Appl. Microbiol. Biotechnol. 49, 258-266.

Jossek, R., and Steinbüchel, A. (1998). In vitro synthesis of poly(3-hydroxybutyric acid) by using an enzymatic coenzyme A recycling system. FEMS Microbiol. Lett. 168, 319-324.

Jurasek, L., and Marchessault, R.H. (2002). The role of phasins in the morphogenesis of poly(3-hydroxybutyrate) granules. Biomacromolecules 3, 256-261.

Jurasek, L., and Marchessault, R.H. (2004). Polyhydroxyalkanoate (PHA) granule formation in Ralstonia eutropha cells: a computer simulation. Appl. Microbiol. Biotechnol. 64, 611-617.

Kichise, T., Taguchi, S., and Doi, Y. (2002). Enhanced accumulation and changed monomer composition in polyhydroxyalkanoate (PHA) copolyester by in vitro evolution of Aeromonas caviae PHA synthase. Appl. Environ. Microbiol. 68, 2411-2419.

Klinke, S., Ren, Q., Witholt, B., and Kessler, B. (1999). Production of medium-chain-length poly(3hydroxyalkanoates) from gluconate by recombinant Escherichia coli. Appl. Environ. Microbiol. 65, 540548.

Klinke, S., de Roo, G., Witholt, B., and Kessler, B. (2000). Role of phaD in accumulation of medium-chainlength poly(3-hydroxyalkanoates) in Pseudomonas oleovorans. Appl. Environ. Microbiol. 66, 3705-3710.

Kraak, M.N., Kessler, B., and Witholt, B. (1997). In vitro activities of granule-bound poly[(R)-3-hydroxyalkan oate]polymerase C1 of Pseudomonas oleovorans-development of an activity test for medium-chainlength-poly(3-hydroxyalkanoate) polymerases. Eur. J. Biochem. 250, 432-439.

Langenbach, S., Rehm, B.H.A., and Steinbüchel, A. (1997). Functional expression of the PHAsynthase gene phaC1 from Pseudomonas aeruginosa in Escherichia 
coli results in poly(3-hydroxyalkanoate) synthesis. FEMS Microbiol. Lett. 150, 303-309.

Lee, S.Y., and Chang, H.N. (1995). Production of poly(hydroxyalkanoic acid). Adv. Biochem. Eng. Biotechnol. 52, 27-58.

Lee, S.Y., and Choi, J.I. (2001). Production of microbial polyester by fermentation of recombinant microorganisms. Adv. Biochem. Eng. Biotechnol. 71, 183-207.

Liebergesell, M., Schmidt, B., and Steinbüchel, A. (1992). Isolation and identification of granule-associated proteins relevant for poly(3-Hydroxyalkanoic Acid) biosynthesis in chromatium-vinosum D. FEMS Microbiol. Lett. 99, 227-232.

Liebergesell, M., and Steinbüchel, A. (1992). Cloning and nucleotide sequences of genes relevant for biosynthesis of poly(3-hydroxybutyric acid) in Chromatium vinosum strain D. Eur. J. Biochem. 209, 135-150.

Liebergesell, M., Mayer, F., and Steinbüchel, A. (1993). Analysis of polyhydroxyalkanoic acid-biosynthesis genes of anoxygenic phototrophic bacteria reveals synthesis of a polyester exhibiting an unusual composition. Appl. Microbiol. Biotechnol. 40, 292-300.

Liebergesell, M., Sonomoto, K., Madkour, M., Mayer, F., and Steinbüchel, A. (1994). Purification and characterization of the poly(hydroxyalkanoic acid) synthase from chromatium-vinosum and localization of the enzyme at the surface of poly(hydroxyalkanoic acid) granules. Eur. J. Biochem. 226, 71-80.

Liebergesell, M., Rahalkar, S., and Steinbüchel, A. (2000). Analysis of the Thiocapsa pfennigii polyhydroxyalkanoate synthase: subcloning, molecular characterization and generation of hybrid synthases with the corresponding Chromatium vinosum enzyme. Appl. Microbiol. Biotechnol. 54, 186-194.

Liu, S.J., and Steinbüchel, A. (2000). Exploitation of butyrate kinase and phosphotransbutyrylase from Clostridium acetobutylicum for the in vitro biosynthesis of poly(hydroxyalkanoic acid). Appl. Microbiol. Biotechnol. 53, 545-552.

Lundgren, D.G., Pfister, R.M., and Merrick, J.M. (1964). Structure of poly-beta-hydroxybutyric acid granules. J. Gen. Microbiol. 34, 441-446.

Lutke-Eversloh, T., Bergander, K., Luftmann, H., and Steinbüchel, A. (2001). Identification of a new class of biopolymer: bacterial synthesis of a sulfur-containing polymer with thioester linkages. Microbiology 147, 1119.

Maehara, A., Ueda, S., Nakano, H., and Yamane, T. (1999). Analyses of a polyhydroxyalkanoic acid granuleassociated 16-kilodalton protein and its putative regulator in the pha locus of Paracoccus denitrificans. J. Bacteriol. 181, 2914-2921.

Maehara, A., Taguchi, S., Nishiyama, T., Yamane, T., and Doi, Y. (2002). A repressor protein, PhaR, regulates polyhydroxyalkanoate (PHA) synthesis via its direct interaction with PHA. J. Bacteriol. 184, 3992-4002.

Matsumoto, K., Takase, K., Aoki, E., Doi, Y., and Taguchi, S. (2005). Synergistic effects of Glu130Asp substitution in the type II polyhydroxyalkanoate (PHA) synthase: enhancement of PHA production and alteration of polymer molecular weight. Biomacromolecules 6, 99104.

Matsusaki, H., Manji, S., Taguchi, K., Kato, M., Fukui, T., and Doi, Y. (1998). Cloning and molecular analysis of the Poly(3-hydroxybutyrate) and Poly(3hydroxybutyrate-co-3-hydroxyalkanoate) biosynthesis genes in Pseudomonas sp. strain 61-3. J. Bacteriol. 180, 6459-6467.

Mayer, F., Madkour, M.H., PieperFurst, U., Wieczorek, R., Gesell, M.L., and Steinbüchel, A. (1996). Electron microscopic observations on the macromolecular organization of the boundary layer of bacterial PHA inclusion bodies. J. Gen. Appl. Microbiol. 42, 445-455.

Mayer, F., and Hoppert, M. (1997). Determination of the thickness of the boundary layer surrounding bacterial PHA inclusion bodies, and implications for models describing the molecular architecture of this layer. J. Basic Microbiol. 37, 45-52.

McCool, G.J., and Cannon, M.C. (1999). Polyhydroxyalkanoate inclusion body-associated proteins and coding region in Bacillus megaterium. J. Bacteriol. 181, 585-592.

McCool, G.J., and Cannon, M.C. (2001). PhaC and PhaR are required for polyhydroxyalkanoic acid synthase activity in Bacillus megaterium. J. Bacteriol. 183, 42354243.

Muh, U., Sinskey, A.J., Kirby, D.P., Lane, W.S., and Stubbe, J. (1999). PHA synthase from chromatium vinosum: cysteine 149 is involved in covalent catalysis. Biochemistry 38, 826-837.

Normi, Y.M., Hiraishi, T., Taguchi, S., Abe, H., Sudesh, K., Najimudin, N., and Doi, Y. (2005). Characterization and properties of G4X mutants of Ralstonia eutropha PHA synthase for poly(3-hydroxybutyrate) biosynthesis in Escherichia coli. Macromol. Biosci. 5, 197-206.

Ollis, D.L., Cheah, E., Cygler, M., Dijkstra, B., Frolow, F., Franken, S.M., Harel, M., Remington, S.J., Silman, I., Schrag, J., and et al. (1992). The alpha/beta hydrolase fold. Protein Eng. 5, 197-211.

Park, S.J., and Lee, S.Y. (2003). Identification and characterization of a new enoyl coenzyme A hydratase involved in biosynthesis of medium-chain-length polyhydroxyalkanoates in recombinant Escherichia coli. J. Bacteriol. 185, 5391-5397.

Peoples, O.P., and Sinskey, A.J. (1989a). Poly-betahydroxybutyrate (PHB) biosynthesis in Alcaligenes eutrophus $\mathrm{H} 16$. Identification and characterization of the PHB polymerase gene (phbC). J. Biol. Chem. 264, 15298-15303.

Peoples, O.P., and Sinskey, A.J. (1989b). Poly-betahydroxybutyrate biosynthesis in Alcaligenes eutrophus H16. Characterization of the genes encoding betaketothiolase and acetoacetyl-CoA reductase. J. Biol. Chem. 264, 15293-15297.

Peters, V., and Rehm, B.H.A. (2005). In vivo monitoring of PHA granule formation using GFP-labeled PHA synthases. FEMS Microbiol. Lett. in press.

Peters, V., Becher, D., and Rehm, B.H.A. (2006). The inherent property of polyhydroxyalkanoate synthase to form spherical PHA granules at the cell poles: The core region is required for polar localization. J. Biotechnol. submitted. 
Peters, V., and Rehm, B.H.A. (2006). In vivo enzyme immobilization by use of engineered polyhydroxyalkanoate synthase. Appl. Environ. Microbiol. 72, 1777-1783.

Pham, T.H., Webb, J.S., and Rehm, B.H.A. (2004). The role of polyhydroxyalkanoate biosynthesis by Pseudomonas aeruginosa in rhamnolipid and alginate production as well as stress tolerance and biofilm formation. Microbiology 150, 3405-3413.

Pieper-Furst, U., Madkour, M.H., Mayer, F., and Steinbüchel, A. (1995). Identification of the region of a 14-kilodalton protein of Rhodococcus ruber that is responsible for the binding of this phasin to polyhydroxyalkanoic acid granules. J. Bacteriol. 177 2513-2523.

Pötter, M., Madkour, M.H., Mayer, F., and Steinbüchel, A. (2002). Regulation of phasin expression and polyhydroxyalkanoate (PHA) granule formation in Ralstonia eutropha H16. Microbiology 148, 24132426.

Pötter, M., Muller, H., Reinecke, F., Wieczorek, R., Fricke, F., Bowien, B., Friedrich, B., and Steinbüchel, A. (2004). The complex structure of polyhydroxybutyrate (PHB) granules: four orthologous and paralogous phasins occur in Ralstonia eutropha. Microbiology 150, $2301-$ 2311.

Pötter, M., Muller, H., and Steinbüchel, A. (2005). Influence of homologous phasins (PhaP) on PHA accumulation and regulation of their expression by the transcriptional repressor PhaR in Ralstonia eutropha H16. Microbiology 151, 825-833.

Prieto, M.A., Buhler, B., Jung, K., Witholt, B., and Kessler, B. (1999). PhaF, a polyhydroxyalkanoate-granuleassociated protein of Pseudomonas oleovorans GPo1 involved in the regulatory expression system for pha genes. J. Bacteriol. 181, 858-868.

Qi, Q., Rehm, B.H.A., and Steinbüchel, A. (1997). Synthesis of poly(3-hydroxyalkanoates) in Escherichia coli expressing the PHA synthase gene phaC2 from Pseudomonas aeruginosa: comparison of PhaC1 and PhaC2. FEMS Microbiol. Lett. 157, 155-162.

Qi, Q., Steinbüchel, A., and Rehm, B.H.A. (1998). Metabolic routing towards polyhydroxyalkanoic acid synthesis in recombinant Escherichia coli (fadR): inhibition of fatty acid beta-oxidation by acrylic acid. FEMS Microbiol. Lett. 167, 89-94.

Qi, Q., Steinbüchel, A., and Rehm, B.H.A. (2000). In vitro synthesis of poly(3-hydroxydecanoate): purification and enzymatic characterization of type II polyhydroxyalkanoate synthases $\mathrm{PhaC} 1$ and $\mathrm{PhaC2}$ from Pseudomonas aeruginosa. Appl. Microbiol. Biotechnol. 54, 37-43.

Qi, Q., and Rehm, B.H.A. (2001). Polyhydroxybutyrate biosynthesis in Caulobacter crescentus: molecular characterization of the polyhydroxybutyrate synthase. Microbiology 147, 3353-3358.

Quaiser, A., Ochsenreiter, T., Klenk, H.P., Kletzin, A., Treusch, A.H., Meurer, G., Eck, J., Sensen, C.W., and Schleper, C. (2002). First insight into the genome of an uncultivated crenarchaeote from soil. Environ. Microbiol. 4, 603-611.
Rehm, B.H.A., Kruger, N., and Steinbüchel, A. (1998). A new metabolic link between fatty acid de novo synthesis and polyhydroxyalkanoic acid synthesis. The PHAG gene from Pseudomonas putida KT2440 encodes a 3-hydroxyacyl-acyl carrier protein-coenzyme a transferase. J. Biol. Chem. 273, 24044-24051.

Rehm, B.H.A., and Steinbüchel, A. (1999). Biochemical and genetic analysis of PHA synthases and other proteins required for PHA synthesis. Int. J. Biol. Macromol. 25, 3-19.

Rehm, B.H.A., Qi, Q., Beermann, B.B., Hinz, H.J., and Steinbüchel, A. (2001). Matrix-assisted in vitro refolding of Pseudomonas aeruginosa class II polyhydroxyalkanoate synthase from inclusion bodies produced in recombinant Escherichia coli. Biochem. J. 358, 263-268.

Rehm, B.H.A., Antonio, R.V., Spiekermann, P., Amara, A.A., and Steinbüchel, A. (2002). Molecular characterization of the poly(3-hydroxybutyrate) (PHB) synthase from Ralstonia eutropha: in vitro evolution, site-specific mutagenesis and development of a $\mathrm{PHB}$ synthase protein model. Biochim. Biophys. Acta 1594, 178-190.

Rehm, B.H.A. (2003). Polyester synthases: natural catalysts for plastics. Biochem. J. 376, 15-33.

Rehm, B.H.A. (2006a). Genetics and biochemistry of polyhydroxyalkanoate granule self-assembly: the key role of polyester synthases. Biotechnol. Lett. 28, 207213.

Rehm, B.H.A. (2006b). Biopolyester particles produced by microbes or using polyester synthases: Selfassembly and potential applications. In: Microbial Bionanotechnology: Biological Self-assembly Systems and Biopolymer-based Nanostructures, ed. Bernd H.A. Rehm: pp 1-34.

Ren, Q., De Roo, G., Kessler, B., and Witholt, B. (2000a). Recovery of active medium-chain-length-poly-3hydroxyalkanoate polymerase from inactive inclusion bodies using ion-exchange resin. Biochem. J. 349, 599-604.

Ren, Q., Sierro, N., Witholt, B., and Kessler, B. (2000b). FabG, an NADPH-dependent 3-ketoacyl reductase of Pseudomonas aeruginosa, provides precursors for medium-chain-length poly-3-hydroxyalkanoate biosynthesis in Escherichia coli. J. Bacteriol. 182, 2978-2981.

Reusch, R.N. (1995). Low molecular weight complexed poly(3-hydroxybutyrate): a dynamic and versatile molecule in vivo. Can. J. Microbiol. 41 Suppl 1, 50-54.

Reusch, R.N., Huang, R., and Bramble, L.L. (1995). Poly-3-hydroxybutyrate/polyphosphate complexes form voltage-activated $\mathrm{Ca} 2+$ channels in the plasma membranes of Escherichia coli. Biophys. J. 69, 754766.

Reusch, R.N., Huang, R., and Kosk-Kosicka, D. (1997). Novel components and enzymatic activities of the human erythrocyte plasma membrane calcium pump. FEBS Lett. 412, 592-596.

Reusch, R.N. (2000). Transmembrane ion transport by polyphosphate/poly-(R)-3-hydroxybutyrate complexes. Biochemistry (Mosc) 65, 280-295. 
Saegusa, H., Shiraki, M., Kanai, C., and Saito, T. (2001). Cloning of an intracellular poly[D(-)-3-hydroxybutyrate] depolymerase gene from Ralstonia eutropha H16 and characterization of the gene product. J. Bacteriol. 183, 94-100.

Schrag, J.D., and Cygler, M. (1997). Lipases and alpha/ beta hydrolase fold. Methods Enzymol. 284, 85-107.

Schubert, P., Steinbüchel, A., and Schlegel, H.G. (1988). Cloning of the Alcaligenes eutrophus genes for synthesis of poly-beta-hydroxybutyric acid (PHB) and synthesis of PHB in Escherichia coli. J. Bacteriol. 170, 5837-5847.

Schubert, P., Kruger, N., and Steinbüchel, A. (1991). Molecular analysis of the Alcaligenes eutrophus poly(3hydroxybutyrate) biosynthetic operon: identification of the $\mathrm{N}$ terminus of poly(3-hydroxybutyrate) synthase and identification of the promoter. J. Bacteriol. 173, 168-175.

Schultheiss, D., Handrick, R., Jendrossek, D., Hanzlik, M., and Schuler, D. (2005). The presumptive magnetosome protein Mms16 is a poly(3-hydroxybutyrate) granule-bound protein (phasin) in Magnetospirillum gryphiswaldense. J. Bacteriol. 187, 2416-2425.

Sheu, D.S., and Lee, C.Y. (2004). Altering the substrate specificity of polyhydroxyalkanoate synthase 1 derived from Pseudomonas putida GPo1 by localized semirandom mutagenesis. J. Bacteriol. 186, 41774184.

Sim, S.J., Snell, K.D., Hogan, S.A., Stubbe, J., Rha, C., and Sinskey, A.J. (1997). PHA synthase activity controls the molecular weight and polydispersity of polyhydroxybutyrate in vivo. Nat. Biotechnol. 15, 6367.

Slater, S.C., Voige, W.H., and Dennis, D.E. (1988). Cloning and expression in Escherichia coli of the Alcaligenes eutrophus $\mathrm{H} 16$ poly-beta-hydroxybutyrate biosynthetic pathway. J. Bacteriol. 170, 4431-4436.

Snell, K.D., Feng, F., Zhong, L., Martin, D., and Madison, L.L. (2002). YfcX enables medium-chain-length poly(3-hydroxyalkanoate) formation from fatty acids in recombinant Escherichia coli fadB strains. J. Bacteriol. 184, 5696-5705.

Soberon-Chavez, G., Aguirre-Ramirez, M., and Sanchez, R. (2005). The Pseudomonas aeruginosa RhIA enzyme is involved in rhamnolipid and polyhydroxyalkanoate production. J. Ind. Microbiol. Biotechnol.

Steinbüchel, A., Aerts, K., Babel, W., Follner, C., Liebergesell, M., Madkour, M.H., Mayer, F., PieperFurst, U., Pries, A., Valentin, H.E., and et al. (1995). Considerations on the structure and biochemistry of bacterial polyhydroxyalkanoic acid inclusions. Can. J. Microbiol. 41 Suppl 1, 94-105.

Stuart, E.S., Tehrani, A., Valentin, H.E., Dennis, D., Lenz, R.W., and Fuller, R.C. (1998). Protein organization on the PHA inclusion cytoplasmic boundary. J. Biotechnol. 64, 137-144.

Stubbe, J., and Tian, J. (2003). Polyhydroxyalkanoate (PHA) homeostasis: the role of PHA synthase. Nat. Prod. Rep. 20, 445-457.

Taguchi, K., Aoyagi, Y., Matsusaki, H., Fukui, T., and Doi, Y. (1999). Co-expression of 3-ketoacyl-ACP reductase and polyhydroxyalkanoate synthase genes induces
PHA production in Escherichia coli HB101 strain. FEMS Microbiol. Lett. 176, 183-190.

Taguchi, S., Nakamura, H., Hiraishi, T., Yamato, I., and Doi, Y. (2002). In vitro evolution of a polyhydroxybutyrate synthase by intragenic suppression-type mutagenesis. J. Biochem. (Tokyo) 131, 801-806.

Taguchi, S., and Doi, Y. (2004). Evolution of polyhydroxyalkanoate (PHA) production system by "enzyme evolution": successful case studies of directed evolution. Macromol. Biosci. 4, 146-156.

Takase, K., Taguchi, S., and Doi, Y. (2003). Enhanced synthesis of poly(3-hydroxybutyrate) in recombinant Escherichia coli by means of error-prone PCR mutagenesis, saturation mutagenesis, and in vitro recombination of the type II polyhydroxyalkanoate synthase gene. J. Biochem. (Tokyo) 133, 139-145.

Tian, J., Sinskey, A.J., and Stubbe, J. (2005a). Detection of intermediates from the polymerization reaction catalyzed by a D302A mutant of class III polyhydroxyalkanoate (PHA) synthase. Biochemistry 44, 1495-1503.

Tian, J., Sinskey, A.J., and Stubbe, J. (2005b). Class III polyhydroxybutyrate synthase: involvement in chain termination and reinitiation. Biochemistry 44, 83698377.

Tian, J., Sinskey, A.J., and Stubbe, J. (2005c). Kinetic studies of polyhydroxybutyrate granule formation in Wautersia eutropha $\mathrm{H} 16$ by transmission electron microscopy. J. Bacteriol. 187, 3814-3824.

Timm, A., and Steinbüchel, A. (1992). Cloning and molecular analysis of the poly(3-hydroxyalkanoic acid) gene locus of Pseudomonas aeruginosa PAO1. Eur. J. Biochem. 209, 15-30.

Tsuge, T., Fukui, T., Matsusaki, H., Taguchi, S., Kobayashi, G., Ishizaki, A., and Doi, Y. (2000). Molecular cloning of two (R)-specific enoyl-CoA hydratase genes from Pseudomonas aeruginosa and their use for polyhydroxyalkanoate synthesis. FEMS Microbiol. Lett. 184, 193-198.

Tsuge, T., Saito, Y., Narike, M., Muneta, K., Normi, Y.M., Kikkawa, Y., Hiraishi, T., and Doi, Y. (2004). Mutation effects of a conserved alanine (Ala510) in type I polyhydroxyalkanoate synthase from Ralstonia eutropha on polyester biosynthesis. Macromol. Biosci. 4, 963-970.

Turk, B., Turk, V., and Turk, D. (1997). Structural and functional aspects of papain-like cysteine proteinases and their protein inhibitors. Biol. Chem. 378, 141-150.

Valentin, H.E., Stuart, E.S., Fuller, R.C., Lenz, R.W., and Dennis, D. (1998). Investigation of the function of proteins associated to polyhydroxyalkanoate inclusions in Pseudomonas putida BMO1. J. Biotechnol. 64, 145157.

Wang, W.S., and Lundgren, D.G. (1969). Poly-betahydroxybutyrate in the chemolithotrophic bacterium Ferrobacillus ferrooxidans. J. Bacteriol. 97, 947-950.

Wieczorek, R., Steinbüchel, A., and Schmidt, B. (1996). Occurrence of polyhydroxyalkanoic acid granuleassociated proteins related to the Alcaligenes eutrophus H16 GA24 protein in other bacteria. FEMS Microbiol. Lett. 135, 23-30.

Witkowski, A., Joshi, A.K., and Smith, S. (1997). Characterization of the interthiol acyltransferase 
reaction catalyzed by the beta-ketoacyl synthase domain of the animal fatty acid synthase. Biochemistry 36, 16338-16344.

Wodzinska, J., Snell, K., Rhomberg, A., Sinskey, A., Biemann, K., and Stubbe, J. (1996). Polyhydroxybutyrate synthase: Evidence for covalent catalysis. J. Am. Chem. Soc. 118, 6319-6320.

Yang, S.Y., and Elzinga, M. (1993). Association of both enoyl coenzyme A hydratase and 3-hydroxyacyl coenzyme A epimerase with an active site in the amino-terminal domain of the multifunctional fatty acid oxidation protein from Escherichia coli. J. Biol. Chem. 268, 6588-6592.

York, G.M., Junker, B.H., Stubbe, J., and Sinskey, A.J. (2001a). Accumulation of the PhaP phasin of Ralstonia eutropha is dependent on production of polyhydroxybutyrate in cells. J. Bacteriol. 183, 42174226.

York, G.M., Stubbe, J., and Sinskey, A.J. (2001b). New insight into the role of the PhaP phasin of Ralstonia eutropha in promoting synthesis of polyhydroxybutyrate. J. Bacteriol. 183, 2394-2397.

York, G.M., Stubbe, J., and Sinskey, A.J. (2002). The Ralstonia eutropha PhaR protein couples synthesis of the PhaP phasin to the presence of polyhydroxybutyrate in cells and promotes polyhydroxybutyrate production. J. Bacteriol. 184, 59-66.
York, G.M., Lupberger, J., Tian, J.M., Lawrence, A.G., Stubbe, J., and Sinskey, A.J. (2003). Ralstonia eutropha $\mathrm{H} 16$ encodes two and possibly three intracellular poly[D-(-)-3-hydroxybutyrate] depolymerase genes. J. Bacteriol. 185, 3788-3794.

Yuan, W., Jia, Y., Tian, J., Snell, K.D., Muh, U., Sinskey, A.J., Lambalot, R.H., Walsh, C.T., and Stubbe, J. (2001). Class I and III polyhydroxyalkanoate synthases from Ralstonia eutropha and Allochromatium vinosum: characterization and substrate specificity studies. Arch. Biochem. Biophys. 394, 87-98.

Zhao, M., Li, Z., Zheng, W., Lou, Z., and Chen, G.Q. (2006). Crystallization and initial X-ray analysis of polyhydroxyalkanoate granule-associated protein from Aeromonas hydrophila. Acta Crystallograph. Sect. F Struct. Biol. Cryst. Commun. 62, 814-819.

Zheng, Z., Li, M., Xue, X.J., Tian, H.L., Li, Z., and Chen, G.Q. (2006). Mutation on N-terminus of polyhydroxybutyrate synthase of Ralstonia eutropha enhanced PHB accumulation. Appl. Microbiol. Biotechnol. 72, 896905.

Zinn, M., Witholt, B., and Egli, T. (2001). Occurrence, synthesis and medical application of bacterial polyhydroxyalkanoate. Adv. Drug Deliv. Rev. 53, 5-21. 


\section{Further Reading}

Caister Academic Press is a leading academic publisher of advanced texts in microbiology, molecular biology and medical research. Full details of all our publications at caister.com

- MALDI-TOF Mass Spectrometry in Microbiology Edited by: M Kostrzewa, S Schubert (2016) www.caister.com/malditof

- Aspergillus and Penicillium in the Post-genomic Era Edited by: RP Vries, IB Gelber, MR Andersen (2016) www.caister.com/aspergillus2

- The Bacteriocins: Current Knowledge and Future Prospects Edited by: RL Dorit, SM Roy, MA Riley (2016)

www.caister.com/bacteriocins

- Omics in Plant Disease Resistance Edited by: V Bhadauria (2016) www.caister.com/opd

- Acidophiles: Life in Extremely Acidic Environments Edited by: R Quatrini, DB Johnson (2016) www.caister.com/acidophiles

- Climate Change and Microbial Ecology: Current Research and Future Trend

Edited by: J Marxsen (2016)

www.caister.com/climate

- Biofilms in Bioremediation: Current Research and Emerging Technologies

Edited by: G Lear (2016)

www.caister.com/biorem

- Microalgae: Current Research and Applications Edited by: MN Tsaloglou (2016) www.caister.com/microalgae

- Gas Plasma Sterilization in Microbiology: Theory, Applications, Pitfalls and New Perspectives Edited by: H Shintani, A Sakudo (2016) www.caister.com/gasplasma

- Virus Evolution: Current Research and Future Directions Edited by: SC Weaver, M Denison, M Roossinck, et al. (2016) www.caister.com/virusevol

- Arboviruses: Molecular Biology, Evolution and Control Edited by: N Vasilakis, DJ Gubler (2016) www.caister.com/arbo

- Shigella: Molecular and Cellular Biology Edited by: WD Picking, WL Picking (2016) www.caister.com/shigella

-Aquatic Biofilms: Ecology, Water Quality and Wastewater Treatment

Edited by: AM Romaní, H Guasch, MD Balaguer (2016)

www.caister.com/aquaticbiofilms

- Alphaviruses: Current Biology

Edited by: S Mahalingam, L Herrero, B Herring (2016)

www.caister.com/alpha

- Thermophilic Microorganisms

Edited by: F Li (2015)

www.caister.com/thermophile
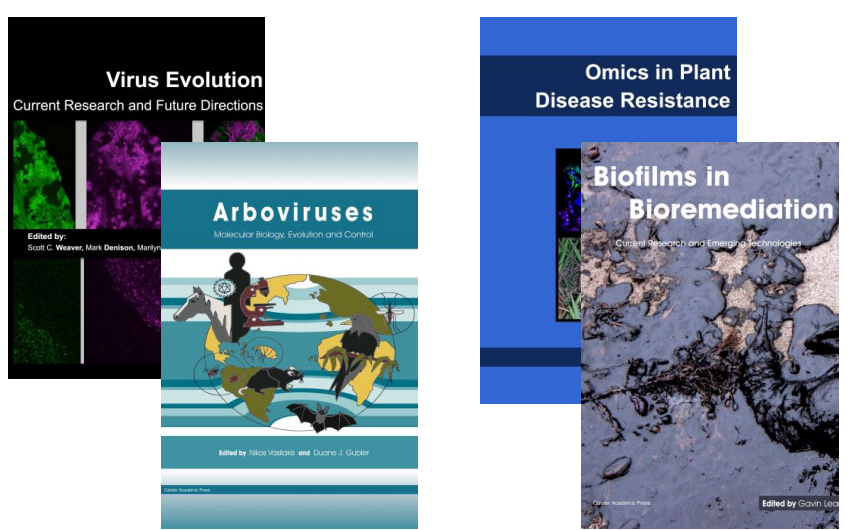
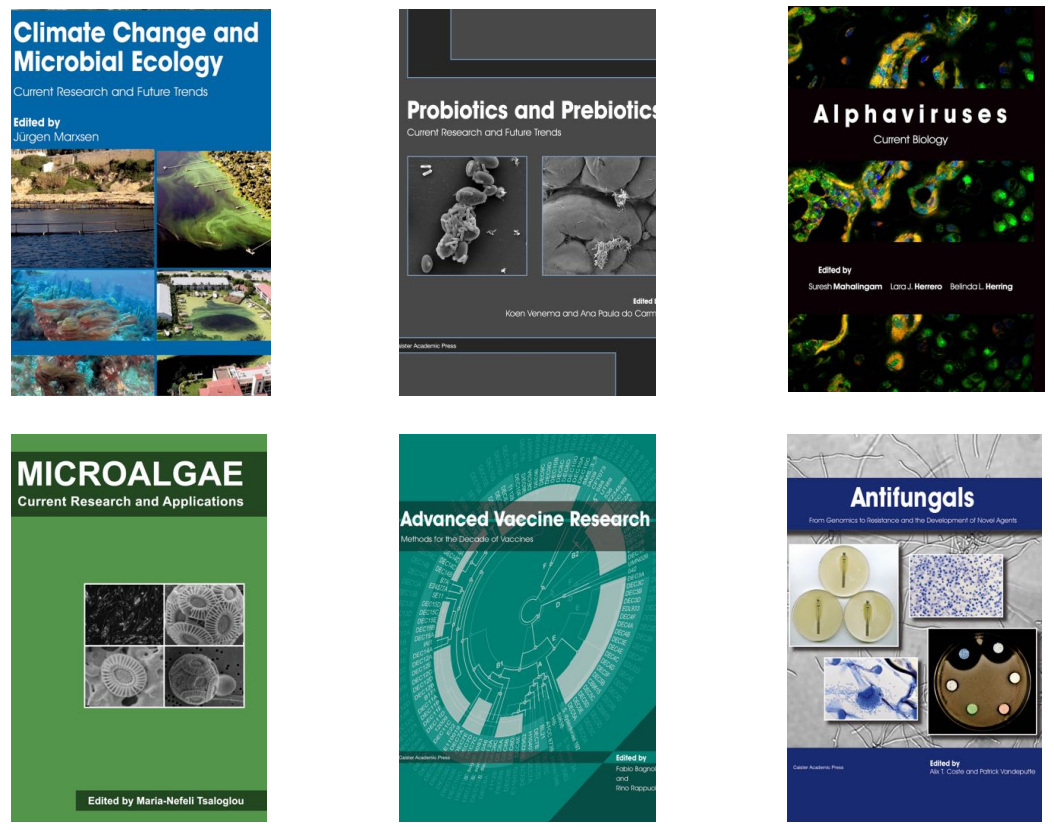

- Flow Cytometry in Microbiology: Technology and Applications Edited by: MG Wilkinson (2015) www.caister.com/flow

- Probiotics and Prebiotics: Current Research and Future Trends Edited by: K Venema, AP Carmo (2015) www.caister.com/probiotics

- Epigenetics: Current Research and Emerging Trends Edited by: BP Chadwick (2015) www.caister.com/epigenetics2015

- Corynebacterium glutamicum: From Systems Biology to Biotechnological Applications

Edited by: A Burkovski (2015)

www.caister.com/cory2

- Advanced Vaccine Research Methods for the Decade of Vaccines

Edited by: F Bagnoli, R Rappuoli (2015)

www.caister.com/vaccines

- Antifungals: From Genomics to Resistance and the Development of Novel Agents

Edited by: AT Coste, P Vandeputte (2015)

www.caister.com/antifungals

- Bacteria-Plant Interactions: Advanced Research and Future Trends Edited by: J Murillo, BA Vinatzer, RW Jackson, et al. (2015) www.caister.com/bacteria-plant

\section{- Aeromonas}

Edited by: J Graf (2015)

www.caister.com/aeromonas

- Antibiotics: Current Innovations and Future Trends

Edited by: S Sánchez, AL Demain (2015)

www.caister.com/antibiotics

- Leishmania: Current Biology and Contro Edited by: S Adak, R Datta (2015) www.caister.com/leish2

- Acanthamoeba: Biology and Pathogenesis (2nd edition) Author: NA Khan (2015)

www.caister.com/acanthamoeba2

- Microarrays: Current Technology, Innovations and Applications Edited by: Z He (2014)

www.caister.com/microarrays2

- Metagenomics of the Microbial Nitrogen Cycle: Theory, Methods and Applications

Edited by: D Marco (2014)

www.caister.com/n2 